\title{
Transformando la matriz heurística de las ciencias sociales. Luces (y sombras) de la investigación naturalista de la cultura
}

Transforming the heuristic matrix of social sciences: lights and
shadows of the naturalistic approaches on culture

Miguel Ángel Castro Nogueira

Doctor en Sociología, ensayista e investigador) mcastron@ono.com (ESPAÑA)

Luis Castro Nogueira

Profesor Titular de la UNED

lcastro@poli.uned.es (ESPAÑA)

LaUREANO Castro NogueIra

Doctor en Ciencias Biológicas. Catedrático de bachillerato e investigador) lcastro@madrid.uned.es (ESPAÑA)

Recibido: 01.03 .2011

Aceptado: 30.11 .2011

\section{RESUMEN}

El intento de Darwin de analizar la cultura y la conducta humana desde un punto de vista naturalista no tuvo una acogida favorable entre la mayor parte de los pensadores que han elaborado los fundamentos de las ciencias sociales. Las tradiciones que configuran el cuerpo central de teoría en las ciencias sociales, el llamado por algunos Modelo estándar (ME), comparten la convicción de que las culturas constituyen sistemas que pueden ser interpretados de manera autorreferencial, sin tener en cuenta las características psicobiológicas de la naturaleza humana. Sin embargo, desde hace unos años, distintas aproximaciones naturalistas han retomada con fuerza el enfoque darwinista e intentan examinar la cultura desde una perspectiva evolucionista. En este artículo, desde una aproximación naturalista propia, basada en lo que denominamos el aprendizaje social assessor y en nuestra radical condición de Homo suadens, establecemos un dialogo crítico con el ME, tratando de mostrar las causas de la obstinada resis- 
tencia que demuestran los individuos cuando se les quiere someter a las categorías, causalidades y determinismos de los discursos científico-sociales del ME, y se les obliga a dejarse narrar por ellos.

\title{
PALABRAS CLAVE
}

Darwinismo, naturalismo, modelo estándar en ciencias sociales, aprendizaje social Assessor, Homo Suadens.

\begin{abstract}
Darwin's attempt to analyze the human culture and behavior from a naturalistic point of view was not sympathetically received by most of the thinkers who have developed the foundations of the social sciences. The traditions that form the main body of social science theory, - the so called Standard Model (SM)-, share the belief that human cultures are systems that can be understood in a selfreferential manner, regardless any psychobiological characteristics of human nature. However, in recent years, different naturalistic approaches try to examine human cultures from an evolutionary perspective. In this article, from our own naturalistic approach, based on what we call social learning assessor and our radical Homo Suadens condition, we set up a critical dialogue with the SM, intending to show the causes of the stubborn resistance shown by individuals when they are subjected to the whole frame of categories, causality and determinism of social scientific discourse and its powerful narratives.
\end{abstract}

\section{KEY WORDS}

Darwinism, Naturalism, Social Science Standard Model, Assessor Social Learning, Homo Suadens.

Este ensayo pretende cubrir dos objetivos ${ }^{1}$. De una parte, contribuir a la difusión en el marco teórico y metodológico del panorama científico-social español de un amplio programa de investigación acerca de la cultura y las prácticas sociales, sorprendentemente poco conocido entre nosotros. Dicho programa, al

${ }^{1}$ Estas páginas constituyen una síntesis parcial de las ideas desarrolladas por los autores en la obra ¿Quién teme a la naturaleza humana. Homo suadens y el bienestar en la cultura: biología evolutiva, metafísica y ciencias sociales, Madrid, Tecnos, 2008, anticipadas, en cierta medida, en Castro, L., Castro, M. A. y Morales, J. Metodología de las ciencias sociales. Una introducción crítica, Madrid, Tecnos, 2005. Las tesis centrales de este ensayo proceden de ella pero se desarrollan ahora con una intención más prospectiva y sugerente, directamente enfocadas a reflexionar acerca del modo en que las ciencias sociales y la investigación naturalista pueden converger en el futuro en algún sentido original y fecundo. 
que nos referimos con el adjetivo naturalista, ocupa un lugar importante en el desarrollo de un prometedor y fronterizo campo de investigación antropológico y social. Desarrollado en el mundo anglosajón, y mucho más tímidamente en el continente europeo, el programa naturalista aporta a las ciencias sociales una nueva visión de la naturaleza de la cultura, y de nuestra naturaleza cultural, a través del estudio de las condiciones filogenéticas que la han hecho posible y de los procesos psicobiológicos que estructuran la mente humana. Más allá de las controversias que este programa suscita por sus ambiciones, unas expectativas que sólo compartimos parcialmente, y por encima del rechazo que el naturalismo (psicobiológico) ha provocado tradicionalmente en el seno de la teoría social, lo cierto es que el programa naturalista puede iluminar con nueva luz algunos de los problemas perennes de la teoría social.

El segundo objetivo a cubrir apunta en una dirección más específica. Establecer un diálogo crítico entre la evidencia acumulada por la investigación naturalista y una de las tradiciones de pensamiento social que ha vertebrado el desarrollo de las ciencias sociales desde sus orígenes. Dicha tradición, a la que nos referimos como Modelo estándar de las ciencias sociales (ME), en expresión de L. Cosmides y J. Tooby (1992), representada paradigmáticamente por E. Durkheim $(1987,1993,1995)$ y las tradiciones de pensamiento holistas, colectivistas, funcionalistas y estructuralistas, no sólo representa el núcleo de la producción sociológica estándar sino que permite visualizar de forma nítida algunas de las limitaciones más importantes con las que se enfrenta toda investigación social o antropológica que se desvincula programáticamente de una consideración empírica y bio-psico-social del individuo, depositando toda su fe científica en el análisis de categorías supraorgánicas y estructurales en tanto que condiciones epistemológicas centrales de toda explicación científico social.

Es precisamente en este punto en el que el programa de investigación naturalista puede aportar una óptica diferente. La gran aportación que un programa de esta naturaleza puede hacer a la investigación social no consiste necesariamente, como podría aventurarse, en una identificación de las condiciones filogenéticas y psicobiológicas que determinan las prácticas sociales de los individuos, o las constriñen - asunto este sobre el que existe una abundante y muy controvertida literatura-, sino en mostrar la impenitente resistencia demostrada por los individuos para someterse dócilmente a las categorías, causalidades y determinismos tan caros a los discursos científico-sociales, y dejarse narrar por ellos. Pues nada resulta más evidente a partir de los resultados de la investigación naturalista, tal y como ésta es interpretada en este ensayo, que la imposibilidad de reducir al individuo a cualesquiera dictados deterministas, vengan estos de la biología o del constructivismo más radical.

\section{INTRODUCCIÓN}

Ch. Darwin ha sido uno de los científicos más influyentes en el desarrollo de

EMPIRIA. Revista de Metodología de Ciencias Sociales. N. ${ }^{\circ}$ 23, enero-junio, 2012, pp. 41-81. ISSN: 1139-5737 
las ciencias contemporáneas. Al contrario que la mayoría de sus contemporáneos, apostó con firmeza por la posibilidad de encontrar una explicación evolutiva para el origen y naturaleza de las facultades morales e intelectuales del hombre, un nuevo abordaje capaz de mostrar que el principio de selección natural es la llave para entender la naturaleza humana.

En sus obras, Darwin esbozó una completa justificación del origen de los instintos sociales y la orientación moral de los seres humanos y creyó posible abordar la cultura y la organización social de las poblaciones humanas, al menos parcialmente, desde un punto de vista naturalista, es decir, a partir de la investigación de las condiciones psicobiológicas que hacen del hombre un ser social, un ser de cultura(s) ${ }^{2}$. Por ello, su influencia ha trascendido el campo de la biología para fecundar otros como la medicina, la psicología, la economía o la sociología, dotándolos de una profundidad temporal y de una heurística nueva y poderosa.

No obstante, a pesar de la fuerza que cobraron las ideas darwinistas en las décadas siguientes a la publicación de sus dos obras más relevantes, El Origen de las especies (1859) y La ascendencia del hombre (1871), lo cierto es que el darwinismo no tuvo una acogida favorable entre la mayor parte de los pensadores que, por aquel entonces, construían los cimientos de las disciplinas sociales. Lamentablemente, la vulgata del llamado darwinismo social pronto desplegó aterradoras afinidades electivas con el racismo, el clasismo y la xenofobia, que probablemente determinaron el rechazo de cualquier consideración sustantiva de la naturaleza humana como parte de las nacientes, —democráticas, emancipadoras-, ciencias sociales ${ }^{3}$.

Incluso, desde la propia biología evolutiva, el paradigma neodarwinista surgido a mediados del siglo pasado y vigente a día de hoy, se ha sostenido que nuestra especie ha sido el fruto de un proceso de evolución biológica sometido a la acción de la selección natural, pero sugiriendo que el extraordinario potencial de nuestro cerebro ha permitido a los seres humanos alcanzar un grado de desarrollo cultural que nos ha independizado en gran medida de nuestra biología (Dobzhanskky, 1973). Los cambios culturales son tan rápidos y su efecto sobre nuestra conducta resulta tan poderoso que, en la práctica, se admite que son los únicos responsables de las diferencias culturales entre sociedades.

${ }^{2}$ La aportación de Darwin a la investigación naturalista de la cultura, en cualquier caso, no debe oscurecer la pertinencia de una investigación social de la génesis del propio pensamiento darwinista, un asunto éste de la mayor relevancia para la ciencia social del que nos hemos ocupado en ¿Quién teme a la naturaleza humana? Homo suadens y el bienestar en la cultura, Madrid, Tecnos, 2008 , pp. 35 y ss.

${ }^{3}$ No podemos dedicar aquí la atención debida a esta cuestión crucial por evidentes razones de oportunidad. Sin embargo, en el texto que sirve de presentación al número, de los mismos autores, se plantea desde una perspectiva histórica más precisa el origen y la pervivencia de esta tendencia en el seno de las ciencias sociales y biológicas, especialmente en relación al nacimiento de la sociobiología en la década de los setenta del pasado siglo. Asimismo, puede consultarse la opinión de los autores en ¿Quién teme a la naturaleza humana? Homo suadens y el bienestar en la cultura, op. cit. capítulos 2 y 10 .

EMPIRIA. Revista de Metodología de Ciencias Sociales. N. ${ }^{\circ}$ 23, enero-junio, 2012, pp. 41-81. ISSN: $1139-5737$ 


\section{2. ¿UN LUGAR PARA LA NATURALEZA HUMANA EN LAS CIENCIAS SOCIALES?}

\subsection{El modelo estándar de las Ciencias Sociales}

Una de las tradiciones centrales del pensamiento social, esa que los psicólogos evolucionistas L Cosmides y J Tooby (1992) han dado en llamar modelo estándar en ciencias sociales ${ }^{4}$ (ME) — simbolizado por el eminente sociólogo E Durkheim y sus actuales herederos-, ha defendido siempre la radical autonomía de los procesos culturales (lo social sólo se explica por lo social), marcando distancias insalvables con otras disciplinas como las ciencias de la vida y la psicología.

Durkheim, en 1895, se expresaba programáticamente en sus Reglas del método sociológico afirmando que se mostraba dispuesto a aceptar la existencia de una naturaleza humana, aunque entendía que

su contribución consiste exclusivamente en estados muy generales, en predisposiciones vagas y, por consiguiente, plásticas, que por sí mismas no podrían tomar aquellas formas definidas y complejas que caracterizan los fenómenos sociales, si no intervinieran otros agentes ${ }^{5}$.

Mucho más recientemente, al calor de la polémica suscitada por la obra de E. O. Wilson Sociobiología: la nueva síntesis, M. Sahlins, uno de los más reputados y lúcidos antropólogos de la segunda mitad del siglo XX, reclamaba para la cultura un estatuto ontológico irreductible a la mirada reduccionista de la biología:

En el hecho simbólico se introduce una discontinuidad radical entre cultura y naturaleza. No existe el isomorfismo entre ambas exigido por la tesis sociobiológica. El sistema simbólico de la cultura no es sólo una expresión de la naturaleza humana, sino que tiene una forma y una dinámica coherentes con sus propiedades en cuanto significativas, lo cual lo convierte más bien en una intervención en la naturaleza. La cultura no está organizada por las emociones primitivas del hipotálamo; son las emociones las organizadas por la cultura ${ }^{6}$.

\footnotetext{
${ }^{4}$ La pertinencia que atribuimos en estas páginas al uso metodológico y limitado, heurístico, de este concepto, modelo estándar en ciencias sociales, no puede oscurecer los manifiestos abusos argumentativos que dicho concepto ha permitido cometer a ciertos autores enmarcados dentro del programa de la psicología evolucionista. Nos referimos muy especialmente a la obra de S. Pinker La tabla rasa, en cuyas páginas esta figura se convierte en la coartada perfecta para reconstruir la historia reciente y remota de las relaciones entre naturalismo y ciencias sociales desde una óptica profundamente ideológica. A este respecto, suscribimos enteramente lo escrito en NIETO, J. A. y CAstro Nogueira, L.: «El Cableado Neuronal Innato de Pinker Repudia la Cultura: Intertextualidad e ínter sexualidad», EMPIRIA. Revista de Metodología de Ciencias Sociales, 11: 133-173, 2006.

${ }^{5}$ E. Durkheim (1987: 117-118).

${ }^{6}$ M. Shalins (1982: 25).
} 
En fin, de esta guisa, entidades supraorgánicas y autorreferentes (descendientes materialistas del Espíritu hegeliano) como la cultura, la estructura social o los campos sociales, se han convertido, dentro de esta tradición, en las únicas sustancias que están detrás, formatean y dan cuenta de fenómenos tan complejos, esquivos y borrosos como la religión, el conflicto social o la ideología. En contra de este Homo sociologicus (cuya otra cara, sólo aparentemente antitética, sería el naturalismo del Homo oeconomicus), sin embargo, ya hace casi cien años, el antropólogo B Malinowski $(1986,1994)$ se había burlado de los paraísos bolcheviques donde, al parecer, habitaban los salvajes fabulados por la tradición académica, subyugados por una igualitaria conciencia colectiva y sin rasgo alguno de individualidad y que en nada se parecían a sus salvajes melanesios cuya espontaneidad, desenvoltura y cinismo nada tenían que envidiar según su expresión- a los american businessmen.

El modelo estándar ha reivindicado la autonomía de los procesos culturales frente a los biológicos. Aunque se ha aceptado sin dificultad que las aptitudes de los seres humanos para la cultura son el resultado de la evolución de nuestro cerebro, se ha mantenido que el aprendizaje social es una capacidad de carácter general, no específica, que permite a los individuos desenvolverse en cualquier cultura si son educados en ella desde niños. Las corrientes holistas dentro de la tradición sociológica consideran a los individuos como recipientes más o menos pasivos de la tradición cultural y asumen que las acciones individuales, salvo las relacionadas con fines biológicos obvios, responden a motivaciones que se encuentran en la propia cultura. La idea de naturaleza humana que manejan, ya sea implícita o explícitamente, describe a los seres humanos, siguiendo los dictados de Locke, como una tabla rasa colonizada por las distintas tradiciones culturales en las que se hallan inmersos los individuos.

Esta imagen de la naturaleza humana y del papel central del aprendizaje social recibió un fuerte impulso de las ideas ilustradas acerca de la plasticidad del ser humano. La maleabilidad de nuestra constitución natural y el peso del ambiente y la experiencia eran hechos demasiado evidentes y poderosos en el agigantado mundo barroco e ilustrado como para dudar de ellos. En cierto sentido, la diversidad cultural fue tomada como un factum a partir del cual pensar la realidad humana.

Al mismo tiempo, la fascinación por la singularidad y la diferencia, sustentada en una incipiente pero abundantísima evidencia etnográfica, no ocultó otro factum tan inquietante como el anterior para la mirada social, pues si la caleidoscópica diversidad cultural resulta sobrecogedora, no es menos cierto que la experiencia cotidiana de cada hombre se sabe regulada por la repetición y la reproducción de las representaciones y las formas de interacción social. La poderosa homogeneidad interna que caracteriza a todo grupo dotado de una mínima identidad social, la prelación de lo colectivo sobre lo personal, el quehacer predecible de los individuos y la reproducción de las formas de dominación fueron percibidos como datos suficientes para dotar de contenido y misión a las nuevas y emancipadoras ciencias del hombre. Y por ello, la convicción de que la cultu-

EMPIRIA. Revista de Metodología de Ciencias Sociales. N. ${ }^{\circ}$ 23, enero-junio, 2012, pp. 41-81. ISSN: $1139-5737$ 
ra precede al individuo y que lo social es lógica y ontológicamente anterior a él constituyó una certeza crucial para esta tradición.

Estas evidencias (heterogeneidad intercultural, homogeneidad y reproducción intragrupales, prelación de lo social) condujeron a la ciencia social decimonónica a adoptar algunos postulados que, desde entonces, se hallan profundamente incorporados a los más diversos saberes acerca del hombre.

El primero no podía ser otro que éste: nuestra naturaleza se caracteriza por una indeterminación esencial que hace de la materia humana la más prima de todas las materias ${ }^{7}$. Una consideración que, realmente, no es fruto de la originalidad del pensamiento moderno, sino, muy al contrario, la herencia de una vieja concepción de la realidad inspirada en el pensamiento clásico y renacentista, pues fue Aristóteles (sobre la base de un platonismo que nunca nos ha abandonado) quien consagró la imagen de un cosmos construido sobre la interacción de dos principios irreductibles: una materia prima definida por su potencialidad infinita - la naturaleza humana en este caso- y una forma estructurante, causa de la identidad sustancial de cada ente — el universo cultural que envuelve y da forma a dicha naturaleza.

El segundo postulado apunta al modo en que habría de ser pensada la cultura, la otra cara de la moneda. La cultura, en tanto que forma, fue presentada como el principio determinante de la potencia natural humana, un principio destinado a in-formar y actualizar la materia prima dotándola de un sentido siempre local. La prelación de las formas culturales sobre toda identidad individual se articuló con una visión de la cultura como realidad superorgánica, una entidad que adviene para modelar la materia humana, estructurándola, constituyendo una identidad a través de un juego de semejanzas y diferencias.

El tercer postulado derivado de esta comprensión de la facticidad social se refiere al elemento dinámico que actúa como mecanismo de retroalimentación, como enlace entre las poderosas fuerzas configuradoras de lo social y la plasticidad humana, garantizando la reproducción de las identidades intragrupales y las diferencias interculturales. Nos referimos a los procesos de aprendizaje agrupados bajo las expresiones socialización y enculturación. Estos fueron concebidos como proteicos y pregnantes procesos de interiorización y modelaje, capaces de penetrar y estructurar la identidad personal hasta armonizarla e integrarla en su comunidad social en tanto que comunidad de creencias, saberes y prácticas $^{8}$.

No es de extrañar, pues, que los psicólogos evolucionistas hayan manifestado su más radical rechazo a estas posiciones fuertemente idealistas y holistas,

${ }^{7}$ Mead (1963: 280, citada por Pinker, 2005, p. 52).

${ }^{8}$ Esta percepción del hombre como un ser hipersocializado y socialmente integrado como consecuencia de la acción coactiva y performativa de los sistemas social y cultural es un viejo tema de debate en las ciencias sociales, especialmente alimentado por las fantasías funcionalistas. Puede encontrarse una revisión crítica de este fenómeno en el texto clásico de D. Wrong «The Overdocialized Conception of Man in Modern Sociology», American Sociological Review, vol. 26, n 2, 1961. 
difícilmente conciliables con la evidencia psicobiológica actual, una nueva visión de la psique humana en la que ésta se nos presenta llena de fracturas, inconsistencias, estructuras modulares y algoritmos de dominio específico fuertemente vinculados a nuestra historia filogenética (Cosmides y Tooby, 1987, 1992, 1994).

El rechazo a la concepción de la naturaleza humana que subyace al modelo estándar en ciencias sociales ha sido recogido, incluso, por los más fervientes críticos del programa sociobiológico. Lewontin, Rose y Kamin en su reconocida y admirada obra No está en los genes (1987), un texto emblemático en el que se expresa una durísima y certera crítica contra ese perverso maridaje entre las pretensiones científicas de la sociobiología — un «gigante con pies de barro»- y ciertos intereses y discursos políticos conservadores y racistas, se manifiestan de forma tajante contra los fundamentos del modelo estándar. Aunque la ciencia social académica ha leído y releído una y otra vez este texto en clave crítica antinaturalista, la obra de estos autores deja bien claro su rechazo a la concepción de la naturaleza humana como una tabla rasa, sumamente maleable, así como frente a las interpretaciones materialistas del marxismo vulgar o los determinismos sociológicos y culturalistas, tan caros al constructivismo social.

\subsection{El reverso del ME y la invención ad hoc de una naturaleza humana: el homo oeconomicus}

No obstante, sería un despropósito reducir la historia de la teoría social (en el sentido más general que podemos atribuir a esta expresión) y de sus relaciones con las ciencias de la vida, a los avatares de este modelo estándar, cuyas huellas podemos rastrear en autores contemporáneos tan influyentes como Parsons, Radcliffe-Brown o Bourdieu, o en clásicos como Marx. Si abandonamos la tradición durkheimiana y exploramos la arquitectura íntima de la teoría económica clásica, más tarde marginalista, podremos observar cómo las ciencias sociales han albergado en su seno, desde muy pronto, la tentación de identificar una peculiar concepción de la naturaleza humana - la del homo oeconomicus - como la ratio essendi de un orden social causado por los efectos no buscados de la actividad individual. Esta imagen de la naturaleza humana, además, se presentaba como la ratio cognoscendi de cualesquiera fenómenos socioculturales mediante un programa de investigación tan seductor y actual como el individualismo metodológico (y su versión más refinada, sutil y formalizada: la teoría de la elección racional).

El individualismo metodológico ha trascendido completamente el ámbito de la microeconomía para postularse como una sólida alternativa al holismo del ME (Hollis, 1998; Gómez, 1997). Sin embargo, a pesar de la poderosa musculatura formal y del complejo aparato matemático que acompañan hoy estos interesantes programas, indispensables en muchos sentidos, se extiende entre los científicos sociales la sospecha de que la imagen del hombre que les da cobertura entra en conflicto con la evidencia empírica que proporcionan biólogos, sociólogos, 
antropólogos y economistas (Elster, 1991, 1997; Boudon, 1998a , 1998b; Aguiar, 2004; Noguera, 2003). Es decir, que la lúcida apuesta por incorporar una concepción de la naturaleza humana al mismo núcleo del pensamiento científico-social no puede articularse a partir de una imagen tan especulativa, limitada e ideológica de la condición humana. Son innumerables, y de procedencia muy diversa, las críticas que ponen en cuestión el manejo que estos programas hacen de nociones tales como racionalidad, creencias, intencionalidad o preferencias, por citar sólo algunos de sus más controvertidos conceptos teóricos (Sen, 1982, 1986; Hollis, 1998; Castro-Nogueira et al., 2005).

La propia investigación psicobiológica y evolutiva, elaborada desde distintos programas de investigación, muestra que, aunque el enfoque individualista proporciona unas herramientas modelo-teóricas muy valiosas, plenamente incorporables a sus modelos, la evidencia disponible no refrenda la autenticidad de una imagen de la naturaleza humana que destaca insistentemente la vertiente egoísta, racional y maximizadora del comportamiento humano. La noción de naturaleza humana que se perfila, incipientemente, a partir de estas investigaciones señala en direcciones diferentes que sólo parcialmente pueden asumir los modelos de comportamiento de la teoría de la elección racional (Tooby y Cosmides, 2005, Hirschfeld y Gelman, 1994; Boyd y Richerson, 1985, 2001; Richerson and Boyd, 2005; Sperber, 2005).

\section{HOMO SUADENS: LAS BASES FILOGENÉTICAS DE LAS CREENCIAS Y LA URDIMBRE ONTOLÓGICA (MICRO)SOCIAL}

En las últimas décadas la separación drástica entre biología y cultura ha sido matizada. Desde la biología evolutiva se ha aplicado la moderna teoría de la evolución al análisis de los procesos culturales, tratando de definir cuáles han sido los factores claves de la transformación de Homo sapiens en la especie cultural por excelencia. Se ha tratado de determinar cuáles son los mecanismos que controlan la transmisión cultural y hacen posible que determinadas conductas, creencias y valores se extiendan en los grupos humanos y, al tiempo, de aventurar una explicación evolutiva para su desarrollo. En general, se acepta que, en especies con una alta capacidad de aprendizaje individual, el desarrollo de un sistema de transmisión cultural puede resultar adaptativo, ya que permite aprovecharse de las conductas desarrolladas por la generación anterior (Lumsden y Wilson, 1981) y reducir el tiempo y los costes que conlleva el aprendizaje individual (Boyd y Richerson, 1985). La ventaja del aprendizaje social radica en que los imitadores observan las conductas que exhiben los individuos imitados que, lógicamente, son aquellas que consideran mejores, aprovechándose así de la experiencia ajena (Rendell et al., 2010). Sin embargo, a pesar de esta ventaja, la cultura sólo ha alcanzado un nivel importante en nuestra especie, sin que esté del todo clara la causa que ha favorecido esta singularidad. Boyd y Richerson 
(1996) y Tomasello (1999) han argüido que la clave que facilitó la evolución de un sistema de herencia cultural como el que poseemos los humanos ha sido un incremento significativo de la capacidad de imitación, unido al desarrollo de la capacidad para elaborar una teoría de la mente.

En este ensayo defendemos la hipótesis de que la evolución de la cultura en nuestra especie necesitó no sólo la capacidad para elaborar una teoría de la mente y un incremento de la habilidad imitativa, sino también la aparición en uno de nuestros antepasados homínidos, al que denominamos Homo suadens (del latín suadeo: valorar, aprobar, aconsejar) o individuos assessor, de nuevas potencialidades cognitivas: en concreto, la capacidad conceptual de categorizar en términos de bueno o malo la conducta propia y ajena y la de transmitir esa categorización aprobando o desaprobando la misma cuando es puesta en acción por otros individuos (Castro y Toro, 1995, 2002, 2004; Castro et al, 2004; Castro et al., 2008). Según nuestro modelo la adopción de una conducta aprendida en primates humanos y no humanos puede ser definida como un proceso con tres etapas. Primera, descubrir y aprender a llevar a cabo una conducta; segunda, poner a prueba y evaluar la conducta aprendida; y tercera, rechazar o incorporar la conducta dentro del repertorio personal de cada individuo. Consideramos que el aprendizaje social, la imitación, representa un mecanismo alternativo al aprendizaje individual para descubrir una conducta dada, pero no compromete la adopción final de la misma. Es decir, los humanos, al igual que los otros primates, deciden incorporar o rechazar una conducta en su repertorio en función del grado de satisfacción o rechazo cuando la explotan. Además, al igual que otros animales con capacidad de aprender, los seres humanos pueden rectificar una decisión de aceptación ya tomada si cambia la recompensa obtenida con el transcurso del tiempo. Como consecuencia, el aprendizaje social por imitación no genera un sistema de herencia cultural en sentido estricto que replica e incorpora sin más lo observado, aunque en apariencia pueda parecerlo.

La capacidad de aprobar o desaprobar la conducta ajena ha sido adaptativa en primer lugar porque permitió transmitir información sobre el valor de la misma entre padres e hijos, condicionando la preferencia de éstos por unas alternativas u otras. Esta transferencia valorativa produce varios efectos favorables: a) incrementa la fidelidad de la transmisión cultural, algo esencial para que el aprendizaje social funcione como un sistema de herencia acumulativo como el humano, ya que cuando la réplica no es fiel el individuo es reprobado y empujado a intentarlo de nuevo; b) permite, cuando hay varias alternativas culturales a las que el individuo puede tener acceso por observación o por aprendizaje individual, una rápida categorización de las mismas como positivas o negativas en función de las preferencias paternas; c) permite controlar la tendencias imitativas y exploratorias de los hijos prohibiéndoles el acceso a conductas que, por su edad, pueden ser potencialmente peligrosas. De este modo se sientan las bases de un sistema de aprendizaje social, el aprendizaje assessor, que adquiere propiedades de un auténtico sistema de herencia cultural al incrementar el parecido fenotípico entre padres e hijos. 
La capacidad de categorizar la conducta propia y ajena permite a los seres humanos aprobar o reprobar la conducta también de otros individuos. Nuestra tesis sugiere que durante la ontogenia la comunicación valorativa entre padres e hijos es sustituida por otra, también en clave valorativa, entre individuos de la misma generación (Castro et al, 2008; Castro et al., 2009; Castro et al., 2010; Castro-Nogueira et al., 2010). De este modo, extendemos el modelo de transmisión cultural assessor entre padres e hijos a otro más general en el cual la aprobación o reprobación de la conducta proviene, además, de otros individuos no necesariamente emparentados entre sí. Cada individuo posee un grupo social de referencia, formado por aquellas personas con las que interacciona de manera preferencial y ante cuya opinión se muestra especialmente sensible: familiares, amigos y colegas. Nuestra propuesta sugiere que los humanos han desarrollado mecanismos psicológicos que nos han hecho receptivos primero a los consejos parentales y, después, a la opinión de los miembros de nuestro grupo social de referencia. La presión de selección que promovió estas nuevas interacciones valorativas está relacionada con la necesidad de establecer interacciones cooperativas para beneficio mutuo más eficaces. Los individuos assessor no pueden evitar percibir la conducta teñida de valor. Cuando interaccionan, están obligados en cierto modo a comparar su conducta con la de sus iguales y a modificarla si la consideran mejor que la propia. Aunque no tengan el propósito de educar como sucede con los hijos, los individuos aprueban o reprueban la conducta de los otros y esto resulta decisivo para el establecimiento de interacciones cooperativas eficaces al propiciar la coordinación a la hora de actuar. Parece razonable asumir que ha evolucionado una tendencia a aceptar las recomendaciones de aquellas personas con las que más estrechamente se relaciona cada individuo, favoreciendo la coordinación y, como consecuencia, la cooperación entre los individuos. Las consecuencias negativas que puede tener la censura social y el ostracismo explicarían la evolución de esta predisposición psicobiológica que busca la aceptación y el reconocimiento de aquellos con los que se interacciona de modo más intenso, lo que se traduce en una tendencia incuestionable a aceptar la influencia social (Waddington, 1960; Simon, 1990; Castro et al., 2009; Castro et al., 2010). Hume, Adam Smith y Darwin, entre otros, detectaron con claridad la presencia en la naturaleza humana de dicha tendencia psicológica que nos permite disfrutar con el reconocimiento social.

Como hemos señalado, la puesta en práctica de una conducta, con independencia de cómo haya sido aprendida, permite que los individuos experimenten las emociones de agrado o desagrado asociadas a su práctica y, a partir de esas sensaciones, tiene lugar su incorporación o rechazo al repertorio conductual. La novedad en el caso humano es que una parte de esas emociones tienen su origen en la aceptación o el rechazo social que produce la conducta. Por tanto, el individuo se encuentra ante dos fuentes de valor cuando experimenta una conducta, una biológica, derivada del placer o displacer directo que produce la misma, y otra social, derivada del placer o displacer que origina su aceptación o rechazo. El Homo suadens interioriza la emoción de placer o desagrado producida social- 
mente como si fuese una propiedad más de la conducta y la utiliza para su categorización como favorable o desfavorable. La lógica subyacente a este proceso, que nosotros denominamos modus suadens, se puede esquematizar como sigue: si una conducta es aprobada, entonces es buena. La eficacia del aprendizaje social assessor reside precisamente en la satisfacción emocional que los individuos experimentan cuando hacen aquello que aprenden que deben hacer, con independencia de cuál sea el contenido concreto de ese deber. De este modo los individuos assessor sienten placer cuando ajustan su conducta a lo que considera correcto su entorno social y, por el contrario, tienen sentimientos de culpa y malestar cuando no es así (Castro y Toro, 1998; Castro et al., 2008; Castro et al., 2010).

El rasgo que singulariza al aprendizaje social humano es, según nuestra tesis, esa capacidad de transmitir información de unos individuos a otros sobre el valor positivo o negativo de determinadas acciones, objetos y organismos. Denominamos creencias a este conjunto de categorizaciones, susceptibles de ser transmitidas culturalmente, que los individuos han adquirido a lo largo su vida. La transmisión cultural de creencias permite la transmisión de información adaptativa entre padres e hijos de carácter instrumental y contenido empírico. Sin embargo, una parte esencial de esa transmisión se refiere a información valiosa sobre cosas que no se pueden hacer; esta información tiene contenido empírico, pero el éxito de la transmisión assessor radica precisamente en sustituir una señal del mundo exterior potencialmente peligrosa por una parental más o menos inofensiva que señala que tal conducta es errónea. Algo similar sucede cuando los individuos se coordinan para cooperar. Sólo los individuos que comparten valores y logran ponerse de acuerdo sobre cómo actuar en una situación dada son capaces de obtener un beneficio mayor cooperando que por separado.

El sistema funciona porque las categorizaciones que generan las creencias se construyen de manera similar a como aprendemos por ensayo y error. Cuando la gente cree algo aceptado como real o verdadero por otros, su mente procesa las emociones sociales que genera esa creencia como evidencia empírica a favor o en contra de la misma. Esto es, el individuo no acepta una creencia de otros individuos como un acto de fe o de mera aceptación de autoridad; el individuo adquiere su creencia sobre el valor de una determinada conducta asumiendo que las emociones sociales de placer o desagrado que genera su acción son el reflejo de una propiedad objetiva de la propia conducta. De este modo, se consigue evitar que los individuos tengan que empezar de cero, evaluando por sí mismos todo lo que descubren u observan sin más ayuda que los dispositivos cognitivos innatos y la propia experiencia personal de cada uno.

La valoración de una conducta no es permanente. Por ejemplo, la sensación de agrado que genera una conducta por sí misma puede disminuir de intensidad o hacerse negativa con el paso del tiempo, o puede surgir una conducta nueva que produzca una satisfacción mayor que la primera y la desplace. Pero el cambio puede proceder también de una modificación del valor transmitido por vía social. Por ejemplo, lo que está prohibido a una edad puede no estarlo más tarde $\mathrm{o}$ viceversa. $\mathrm{O}$ puede modificarse el entorno social en el que se desenvuelve un 
individuo, de manera que en el nuevo entorno exista una categorización mayoritaria diferente de determinadas conductas. Nótese que un cambio de entorno no significa necesariamente un cambio de población; basta con que cambien las personas con las que el individuo interacciona de manera directa: su pareja, sus amigos o compañeros, es decir, su grupo social de referencia. En todo caso, la conducta que finalmente adopte un individuo se considerará como buena frente a la otra y podrá transmitir esta nueva categorización, esta nueva creencia, a otros individuos en sucesivas interacciones.

Cualquier sistema de creencias se constituye en torno a tres elementos: lo que el creyente cree - el contenido de la creencia-, lo que hace como creyente - es decir, sus prácticas - y lo que siente y experimenta cuando piensa y actúa como creyente. El aprendizaje social de un sistema de creencias surge de la interacción entre estos tres elementos, de manera que la verdad de los contenidos y lo adecuado de las acciones están inevitablemente unidos a las emociones que genera su puesta en práctica, parte importante de las cuales provienen de la retroalimentación social. Una vez puesto en marcha el sistema de transmisión cultural assessor, pueden surgir creencias no instrumentales, sin contenido empírico, que una vez categorizadas como verdaderas, como buenas, pueden ser transmitidas en estos mismos términos y propagarse en una población. El sistema de transmisión de creencias puede funcionar al margen de los contenidos concretos de cada una. Esto explica el carácter contingente de buena parte de los rasgos culturales en las sociedades humanas y su escasa correlación, en muchos casos, con un valor biológico adaptativo. Por otra parte, la importancia de la cooperación para la supervivencia humana ha favorecido el ostracismo y el castigo de aquellos individuos que no comparten valores y van por libre dentro de un grupo de interacción. Esta circunstancia aumenta la homogeneidad cultural dentro de sociedades al tiempo que la variabilidad entre sociedades. En cualquier caso el punto clave son los grupos sociales de referencia de cada individuo; esto explica por qué comunidades con valores culturales muy diferentes pueden convivir sin a penas influencia mutua siempre y cuando exista poca permeabilidad social a la hora de configurar el grupo social de referencia de cada individuo.

La transmisión de creencias influye de manera decisiva en la evolución cultural de las sociedades, ya que condiciona el comportamiento de los individuos. Todas las sociedades humanas han construido sistemas de creencias y valores a partir de los cuales pueden discriminar, con apariencia de objetividad, sobre lo correcto o incorrecto del comportamiento humano. El aprendizaje de estas creencias y valores con los que evaluamos el mundo se produce a través de un influjo social continuo. Ahora bien afirmar que el aprendizaje assessor funciona generando creencias que el individuo percibe como verdaderas gracias a la influencia social, no es, claro está, lo mismo que afirmar que todo lo que se aprende tiene realmente la misma consideración de veracidad objetiva. Los seres humanos a lo largo de la historia han sido capaces de establecer principios axiomáticos y reglas de inferencia, como se hace en lógica y matemáticas, o criterios de falsación, como se hace en ciencia, que funcionan como brillantes ha- 
llazgos epistemológicos, a partir de los cuales se puede discriminar con racionalidad entre unas creencias y otras. Sin embargo, sólo una parte del conocimiento se refiere a proposiciones lógicas o a hechos y es, en principio, contrastable. No parece sencillo encontrar otros principios con vocación de universalidad que nos permitan extender el ámbito de aplicación de la razón e ir más allá de lo conseguido en las ciencias exactas y experimentales.

\section{LAS LIMITACIONES TEÓRICO-METODOLÓGICAS DEL ME A LA LUZ DE LA HEURÍSTICA DEL PROGRAMA NATURALISTA}

A la usanza de esos dibujos reversibles en los que se alternan un severo rostro barbado masculino y un seductor desnudo femenino, así ha sucedido y sucede con las imágenes del hombre y de la sociedad suministradas por el ME si las comparamos con las de otra tradición vinculada al arte, la literatura y las humanidades. En la primera imagen (dominante desde K Marx a E Durkheim y P Bourdieu) apenas queda vestigio alguno de naturaleza humana, convertida en una porosa e inerte tabula rasa sobre la cual se inscribe la sombra clonadora de Lo Social tout court. En la segunda, sin embargo (la que brota de las obras de Erasmo, Cervantes, Maffesoli o Todorov), lo que se vislumbra más bien, por el contrario, es una activa, prolífica, imprevisible y dionisíaca condición humana capaz de simpatizar, mimetizar y entrar en flujo con todo género de deseos, quimeras, prácticas e ilusiones compartidas con ciertos individuos y/o pequeños grupos con los que se identifica el sujeto. Como dictamina lúcidamente $\mathrm{M}$. Maffesoli a propósito del ethos posmoderno - pero que podemos hacer extensible a todo momento histórico:

Existe un hedonismo de lo cotidiano, irreprimible y potente, que subtiende y sostiene a toda vida en sociedad. En ciertas épocas, este hedonismo será marginado y ocupará un rol subalterno; habrá otras en las que, por el contrario, será el pivote a partir del cual se ordene, de manera anunciada, discreta o secreta, toda la vida en sociedad. En este preciso momento, eso que uno llama las relaciones sociales, las de la vida común y corriente, las de las instituciones, del trabajo, las del tiempo libre, ya no están únicamente regidas por instancias dominantes, a priori y mecánicas; tampoco están ya orientadas hacia un objetivo por alcanzar, siempre lejano, en suma, todo lo que está delimitado por una lógica económico-política, o determinado en función de una lógica moral. Por el contrario, estas relaciones se vuelven relaciones animadas por y a partir de lo que es intrínseco, vivido día a día, de una manera orgánica; además, se centran de nuevo en aquello que es del orden de la proximidad. En pocas palabras, el vínculo social se vuelve emocional. De esta manera se elabora una manera de ser (ethos) en la que lo primordial será lo que se experimenta con el otro, y que designaré con la expresión» ética de la estética». (Maffesoli, El crisol de las apariencias, 2007, p. 11)

Desde A Smith, GWF Hegel y R Girard, —en una línea secretamente com- 
patible con las intuiciones del propio Darwin sobre la crucial relevancia filogenética de la simpatía - las ciencias humanas siempre han barruntado que el deseo del hombre es un deseo aprendido: el deseo del otro; el deseo de poseer y exhibir aquello que suscita el deseo de los otros y ser reconocido por ellos. Después de todo, quizás, lo más distintivo del hombre sea su condición de Homo Suadens. Estudios recientes sobre psicología evolucionista y transmisión cultural insisten en que la verdadera clave de la hominización no ha sido la aparición de la razón y el lenguaje sino, mucho antes, las ciegas sensaciones de placer que acompañan ciertas conductas cuando son objeto de aprobación por el grupo de referencia, tal y como hemos intentado evidenciar en la sección anterior.

Uno de los problemas esenciales del ME, a nuestro juicio, estriba en que sólo contempla la socialización a partir de un eje ideal, enteramente pasivo, entendido como absorción escolástica - por cada individuo-materia prima y con la misma, indeleble, implicación e intensidad afectivas - de una forma sustancial (cultura, estructura o institución social) que se impone coactivamente sobre cada sujeto. Sin embargo, para entender algo de la verdadera complejidad social y de su riquísima ontología es necesario enriquecer y transformar esta visión unilateral con otras perspectivas tanto o más decisivas que ésta.

Desde luego, tal y como han reivindicado M Foucault $(1981 ; 2006)$ y, en su estela, los teóricos del Actor-Red como B Latour, es imprescindible reconocer el papel fundamental de lo material, técnico y arquitectónico, así como de la dimensión ético-estética de seducción y fascinación colectiva de «lo social» ligado al Saber-Poder. Resulta incuestionable la necesidad de atribuir agencia a toda clase de artefactos y objetos naturales que, a pesar de su condición de seres inanimados pueden producir, y de hecho lo hacen, efectos de extraordinario valor en el curso de los procesos en los que se ensambla y desensambla lo social. Otro tanto ocurre, con nuestra representación del poder como la mera potestas, fatal y centralizada, de los aparatos represores del Estado o de otras macro-instituciones capaces de imponer sus intereses sobre individuos, naciones o mercados. Pues el poder, como ha mostrado lúcidamente Foucault, se despliega por todos los poros del tejido social, constituye subjetividades, verdades y placeres e invade y contamina de alguna manera cualesquiera relaciones humanas (desde el ámbito de la política al de la ciencia y la sexualidad), embrujando y erotizando todo aquello que toca.

Sin embargo, no basta con esta ampliación de nuestra mirada, pues, por otra parte, resulta crucial cruzar aquel primer eje que nace de la poderosa facticidad de lo social con otro muy diferente de orden bio-socio-espacial ${ }^{9}$. De este modo, sin que las sustancias sociales (escuelas, empresas, iglesias, universida-

${ }^{9}$ Para aclarar el significado de expresiones centrales en nuestra argumentación tales como «espacio-tiempo social» o perspectiva «bio-socio-espacial» remitimos a CASTRO, L., La risa del espacio, Madrid, Tecnos, 1997, así como a CASTro, L., CAstro, M. A. y Morales, J. Metodología de las ciencias sociales. Una introducción crítica, Madrid, Tecnos, 2005. 
des, instituciones políticas, centros comerciales o burocracias), pierdan un ápice de sus poderes virtuales de sujeción sobre los individuos, es menester enfatizar el hecho de que éstos las experimentan y refractan de formas muy diversas cuando se envuelven, lían y enrollan entre ellos - como una colonia de algas- en forma de amistades íntimas o burbujas amorosas (P Sloterdijk, 2000, 2003, 2004, 2006), pero también de cómplices, compinches, camaradas, correligionarios y variopintos grupos de creyentes en flujo en el seno de las abigarradas y mestizas texturas y curvaturas del espacio-tiempo social (ETS), creando todo género de entrañables (literalmente), frágiles, imprevisibles y cambiantes habitanzas, grumos y redes.

Miles de ejemplos nos rodean (literalmente) que ponen de manifiesto esta triple naturaleza de lo social (la de la facticidad durkheimiana, la de la dialéctica entre actantes de muy diverso tipo y procesos y, en fin, la propiamente bio-socioespacial). En otro lugar hemos descrito detalladamente, con este mismo propósito, el castizo, y hoy cosmopolita y multicultural, barrio de Lavapiés como un singular e hiperdenso recorte del ETS. En él pueden leerse, de una parte, las fatales huellas de las fuerzas estructurales que, estas sí, de arriba abajo, desplazan enormes poblaciones de unos lugares del mundo a otros en busca de un porvenir imaginario, poblaciones sedimentadas y arracimadas mediante un juego de semejanzas y diferencias identitarias en enclaves urbanos deteriorados en proceso de recreación; de otra, la interpretación topológica de tales procesos, traducibles en una geografía precisa y significamentosa en la que la materialidad urbana cobra un papel crucial en la creación del orden y la regulación de las relaciones e intercambios sociales. Y, por último, una inagotable dinamis social, la propia de las ligaduras microsociales, capaz de hacer surgir, en un mismo espacio físico, formas delirantemente diversas de vida en común, que se extienden desde los tejidos marginales dedicados al tráfico de drogas, el trapicheo y la prostitución, a la exuberante productividad religiosa islámica, budista o evangélica, pasando por la alegría posmoderna de los deleuzianos okupas de El Laboratorio o la gestación de elementales pero muy eficientes células yihadistas, autoras de los atentados terroristas de nuestra historia reciente. Esta diversidad, inabarcable desde un único punto de vista, confirma la imposibilidad de reducir la mirada social a la scholastic view del ME, al tiempo que afirma la necesidad de atender urgentemente a la potencialidad que anida en las envolturas micro-socio-espaciales en las que se juega, de facto, toda pertenencia, toda identidad, toda representación social.

Estas envolturas e impliegues burbujeantes poseen unas singulares atmósferas semiótico-materiales que no sólo vienen cargadas por el poder de diferentes individuos, lugares, objetos, prácticas y placeres, sino también por la circulación local y diferencial de nubes de dispositivos y paquetes de subjetivación que las constituyen y atraviesan y que son objeto de imitación por grupos e individuos: pieles y sensibilidades artificiales, software(s) de la risa y de la culpa, artes de la presentación y relación con uno mismo y con su grupo de referencia, componentes emocionales, paquetes de memorias, delirios e ilusiones colectivas y arsenales discursivos. 
Nos hallamos en el mundo denso y viscoso (C Geertz, 1973) de las significaciones sociales, entreveradas con valores, representaciones, juegos de poder, intereses, prácticas, artes de la vida cotidiana, hábitos y costumbres. Desde esta perspectiva, carece de sentido cualquier estricto determinismo o mecanicismo a la hora de explicar (de arriba abajo) la acción social. Se trata, más bien, como había defendido la gran tradición hermenéutica, de comprenderla. Y ello significa verla desde dentro, desde los modelos que cada sujeto ha internalizado de las estructuras, instituciones y expectativas normativas. Nos hallamos, también, en un mundo irreductible a algoritmos optimizadores o maximizadores; un mundo atravesado de parte a parte por la ambigüedad, la puesta en escena, el poder, la seducción histriónica, la fascinación recíproca y la libertad. Nos hallamos en el mundo de los juegos del lenguaje estudiados por Wittgenstein y su escuela: en el peculiar mundo de los funcionarios de un ayuntamiento, de los religiosos de un colegio, de los albañiles de una obra, de los profesores universitarios, de los médicos de hospital, de los artistas o de los cantantes pop.

Naturalmente, este segundo eje bio-socio-espacial, tan hipersensible a las condiciones iniciales, introduce derivas caóticas, autopoiéticas (en el sentido de la Chaos Theory) que otorgan una enorme vitalidad y complejidad plástica impredecible al ETS, a sus tramas y nervaduras y a toda su deslumbrante nano-ontología. Algo que, por lo demás y desde siempre, han intuido la mayoría de los seres humanos y explorado los artistas, dramaturgos, cineastas y novelistas pero que, sin embargo, jamás han querido reconocer los científicos sociales, perfectamente envueltos (¡esta vez sí!) tan a menudo en sus propias, tautológicas, edificantes y ebúrneas torres académicas.

¿En qué consisten, pues, los excesos del ME que a menudo empañan sus indudables logros y aciertos? En el síndrome denunciado por Malinowski: en su hybris autoritaria y determinista insensible a las diferencias entre esas microenvolturas. Porque sin tomarse en serio esa naturaleza suadens - tan imprevisible e inconstante en sus deseos, afectos, juicios y creencias-, no se entendería nada de la inagotable diversidad de experiencias y derivas a través de las cuales los sujetos han vivido y siguen viviendo, ahora mismo, no sólo la religión y la política — desde el fanatismo hasta el desprecio o la indiferencia-, sino también las leyes de la vida económica: ¿cómo no recordar en estos momentos de zozobra financiera los animal spirits keynesianos responsables de tantas crisis y fluctuaciones en mercados pretendidamente autorregulados? Ni tampoco podría comprenderse la creatividad (por chapucera que sea) con la que esos mismos sujetos gozan, imitan, —y se dejan hechizar por- ambientes, artistas, objetos, teorías, prácticas, modas y sensibilidades en las actuales culturas (mestizas, híbridas) posmodernas, irreductibles a cualquier lógica de calco estructural y distinción clasistas.

Así pues, ya va siendo hora de reconocer,- como un mínimo homenaje a las intuiciones del viejo Darwin-, que la fuerza que sostiene detrás de las apariencias ilusorias a la religión, el arte, la metafísica y tantas otras creaciones humanas, no sólo procede de las férreas estructuras sociales, sino también de la 
prodigiosa virtualidad de esa otra naturaleza humana, radicalmente darwinista que, — como retorno de lo reprimido—, sigue prestando toda su cándida solidez, aura y hechizo a las viejas, autistas, ilusorias, burbujas y envolturas humanas.

\subsection{El espejismo de la autonomía cultural}

La quimera de la autonomía de la cultura del modelo estándar en ciencias sociales (ME) procede del poder esencializador sobre el imaginario de la gente ordinaria -y de los científicos sociales- que poseen algunas estructuras e instituciones sociales (como la esclavitud griega, la religión islámica o el sistema de castas en la antigua India). Tales catedrales (como diría G Tarde, 1890, 1898) parecen proyectar su sombra sobre todos y cada uno de sus moradores determinando en todos ellos por igual idénticas experiencias, valores, creencias, deseos y emociones. Sin embargo, esto no es más que un espejismo de la hipertrofia cultural creada por ese mismo ME. En realidad, el poder innegable de las grandes estructuras, instituciones y significaciones sociales se parece más bien, en muchos casos, al que poseen fenómenos externos materiales: físico-arquitectónicos, meteorológicos, geomorfológicos y geográficos por lo que implican todos ellos de profunda curvatura global semiótico-material del ETS, y con todo lo que sin duda comporta esa curvatura de imposición de trayectorias posibles por el ETS, prohibiciones y tabúes, re-producción de pautas de dominio y explotación, habitus en el sentido de Bourdieu y formidables inercias al servicio del poder establecido.

De eso no hay duda, pero esa curvatura global sólo existe y se experimenta por los sujetos que la sufren y gozan, sub specie bullae, es decir, bajo todo tipo de burbujas, entramados emocionales y envolturas rabiosamente locales, evanescentes, magmáticas y contradictorias. La curvatura global recoge las características esenciales de los llamados hechos sociales durkheimianos: su relativa independencia y exterioridad de los individuos empíricos ya que, como reconocen B Latour y Foucault, tales características se hallan formateadas no sólo por interacciones reguladas, normas, valores y leyes introyectados y metabolizados como una segunda naturaleza sino también por materialidades naturales y objetos físico-arquitectónicos con agencia; y se reproducen y mantienen por todas aquellas inconscientes, habituales, microconductas, rutinas e inercias, producto a la vez y de forma inseparable tanto de coacción/represión como de aprendizaje social suadens e imitación - que le otorgan su peculiar, relativa, (in)consistencia. Es decir, por su innegable poder coactivo pero también por su poder de contagio, seducción/repugnancia (corrigiendo a Durkheim y dándole la razón a $\mathrm{G}$ Tarde ${ }^{10}$ ) sobre los sujetos.

${ }^{10}$ Las tesis defendidas en este artículo coinciden, en sus intuiciones y sólo parcialmente, con las defendidas por G. Tarde en su polémica con Durkheim acerca del papel de la imitación y contra la perspectiva sustancialista y platónica que adoptan ciertos conceptos en la sociología 
Ahora bien, —nuevamente más acá de Durkheim—, esos hechos sociales así definidos en tanto que puras exterioridades coactivas más o menos interiorizadas, - actuando al modo de formas sustanciales masculinas sobre una pisicología individual concebida escolásticamente como materia prima femenina infinitamente moldeable - , no son ni constituyen más que una parte de la fenomenología social, siendo la otra la experiencia vivencial activa, praxeológica, afectiva, individual y grupal (espontánea, polimórfica, creadora y fabuladora) de esas mismas ( $\mathrm{i}$ !) estructuras e instituciones que constituye, precisamente, la triple respuesta más o menos inconsciente (de sujetos y pequeños grupos) a las siguientes interrogantes: a) ¿dónde estamos?, b) ¿quiénes somos?, c) ¿qué podemos/debemos hacer?.

Y si la curvatura global se ha expresado tradicionalmente en términos del Poder (Potestas) de las grandes estructuras e instituciones sociales in-corporadas por los sujetos e inscritas en la materialidad física (arquitectónica) de las sociedades, la segunda curvatura local (en tanto que giro copernicano desde el cual se experimenta la primera) debería expresarse en términos simétricos como el (contra)Poder (Potentia spinoziana aludida por G Tarde, I Joseph, M Maffesoli, $\mathrm{J}$ Rancière, M Delgado) de las resistencias y distorsiones ofrecidas por los egos múltiples, frágiles, inconsistentes y modulares vinculados por la socialidad originaria a través de la cual se experimentan, re-presentan y vivencian todas aquellas instituciones sociales.

Sin esto no puede concebirse ni explicarse (frente al habitus clonador, reproductor, estructural, domesticador y modelador de pretendidas servidumbres voluntarias) las revoluciones, revueltas, malestares y repentinas rebeldías pero también y, sobre todo, las formidables indiferencias y rutinas que caracterizan en general a las sociedades humanas frente a los poderes, represiones y coacciones sociales.

Todo el proyecto del ME al hipostasiar y reificar la indiscutible, brutal, fuerza estructural de exterioridad coactiva como única productora de subjetividad, normas y valores no ha pretendido otra cosa en el fondo que silenciar y forcluir, finalmente, esa otra perplejidad decisiva para cualquier observador de la vida social, mínimamente consciente de lo que se esconde tras los mil mundos pre-subjetivos (individuales y sobre todo de pequeños grupos) compatibles con el habitus de unas estructuras siempre infradeterminantes.

En el fondo, el ME a menudo no funciona más que como una prohibición firmemente anclada en sus métodos constructivos de (pseudo)análisis social mediante encuestas y estadísticas cuidadosamente diseñadas para no encontrar nada que no esté ya implícito, preformateado, en las preguntas - de cualquier

durkheimiana. También, más recientemente, con las defendidas por B. Latour, al que citamos en varias ocasiones. A propósito de esta coincidencia puede consultarse CASTRO, M. A., CASTRO, L. y Toro, M. A., «Evolución y cultura: una aproximación naturalista a las ciencias sociales», Endoxa: series filosóficas, $\mathrm{n}^{\circ} 24,2010$, pp. 219-245, UNED. Apropósito del debate entre Tarde y Durkheim véase CASTRO, L. et al., «Darwinismo y ciencias sociales: una interpretación evolucionista de la cultura», Ludus vitalis, vol XVII, nº 32, 2009, pp. 281-306. 
afloramiento de esos mundos subterráneos, efímeros, monstruosos y volátiles que se ocultan en la polimórfica experiencia de unos egos y pequeños grupos atravesados por la alteridad y la labilidad y de una socialidad originaria surcada por una promesa infinita de diferencias mutantes (como ya mostraron en su día los autores que acabamos de mencionar pero también G Simmel, Goffman, Garfinkel, H Lefebvre, N Elias y tantos otros investigadores ${ }^{11}$ ). El día que se use todo el potencial de los métodos cuantitativos y cualitativos para explorar verdaderamente la distancia de los individuos con las instituciones y grandes significaciones sociales, las CCSS podrían comenzar de nuevo vacunadas definitivamente contra sus totalitarias ilusiones de partida.

El ME deja de respirar cuando respiran los nativos y, a la inversa, cuando el ME respira a pleno pulmón la atmósfera (para cualquier nativo y no se olvide que todos somos nativos) se hace irrespirable. El ME ha surgido como el intento de abolir cualquier complicación que ponga de manifiesto que cuando sienten, actúan y hablan los nativos, una parte esencial de ese sentir, actuar y hablar es tan ambiguo, irreductible y contradictorio como el del propio científico social que trata de objetivarlo: unos y otros poseen una misma musical, ambigua, condición humana.

Lo que se pone de manifiesto en la relación entre antropólogos y nativos es que al margen de las diferentes partituras que interpretan, ambos participan de una misma música callada que excede la literalidad de aquellas partituras. Y eso mismo, el atisbo de esa intolerable perplejidad que barrunta, a veces, el estudioso (la perplejidad de cualquier ser humano ante otro que le parece tan diferente como - secretamente- idéntico a él mismo) es lo que enlaza el colonialismo con la ciencia social: la negativa a reconocer que el exceso de subjetividad de los nativos (imposible de alojar enteramente en las estructuras sociales a las que desborda una y otra vez) es el mismo que su propio exceso como antropólogo propietario de una mirada tan distante como compleja y contradictoria.

También son innumerables sus motivos para estudiar a los aborígenes que no caben (ni se disuelven enteramente) en el oficio que practica: sus ilusiones profesionales, sus creencias en cierta escuela metodológica, sus deseos de vivir otras experiencias, su espíritu de aventura, sus pasiones de voyeur, etc. Y por parte del nativo (como decía Wittgenstein en los comentarios a la Rama dorada) tampoco se agotan sus prácticas y creencias en las anotaciones del antropólogo en torno a

${ }^{11}$ Las objeciones críticas que se plantean en este ensayo al modelo estándar de las ciencias sociales se articulan desde una perspectiva naturalista, la que es objeto de análisis en este artículo. Es obvio que desde otras posiciones, particularmente esas que se han denominado comúnmente microsociológicas -interaccionismo, etnometodología, sociología del conflicto, etc.—-, pero también desde la reflexión de quienes han incorporado la historia como condición necesaria para comprender la realidad social, se han formulado objeciones no menos interesantes y, en buena medida, compatibles con las propuestas aquí por los autores. Una revisión completa de la tradición «estándar»en las ciencias sociales obligaría a visualizar todas esas tradiciones y programas de investigación, una tarea que queda fuera de nuestro alcance en estas páginas. Merece una mención especial, dentro de este panorama crítico y sensible a la materialidad somática de la vida, N. Elias. Véase nuestro punto de vista al respecto de este autor en CASTRO, L., CASTRO, M. A. y Morales, J., op. cit. cap. 16. 
sus supersticiones mágicas, sus creencias en dioses o demonios o sus rituales de purificación: también el nativo excede esos alojamientos a donde le conduce el antropólogo, también el nativo en su distancia con las Grandes Significaciones que le atribuye el antropólogo es nuestro hermano, tan nuestro al menos como nosotros somos nuestros de nosotros mismos.

El antropólogo intenta un vaciado completo del alma del aborigen despojándola de toda singularidad y empaquetándola (disolviéndola) en las instituciones del mismo modo que la polis trata de apoderarse de la alteridad de lo urbano y el Estado colonizar la sociedad civil. Nada tiene de extraño que según P. Clastres en las sociedades amerindias la constante guerra civil sea el único instrumento que les impide o les salva a los indígenas de devenir Estado ni que los movimientos, inorgánicos, inciertos, salvajes, oscuros, ciudadanos, urbanos, tan efímeros como contundentes se usen como exorcismo del sueño de toda Polis-Estado; ni que cuando, en fin, los antropólogos y demás científicos sociales dejen hablar a los aborígenes una parte de su ciencia pase de inmediato a mejor vida.

\subsection{El Poder en las ciencias sociales: represión/construcción de la naturaleza humana}

Así pues, por el lado del Poder, —en tanto que incuestionable objetividad social anclada siempre en un ETS del cual es causa y efecto a la vez: un aula de la ESO, una oficina, una parroquia, una UCI, un laboratorio, una cárcel, la sede de un sindicato o de una checa-, es menester reconocer tanto sus dimensiones dukheimianas estructural-coactivas (normativas, discursivas, jurídico-punitivas) interiorizadas en forma de habitus (Bourdieu), como las arquitectónicas físicomateriales disciplinares (Foucault, Latour) y las propias de su función estéticocreativa y productiva forjadoras de subjetividad, discursos y placeres (Foucault) que le imprimen tan a menudo un carácter de fascinación colectiva, mientras que por el lado de la experiencia bio-socio-espacial del mismo habría que señalar al menos varias formas tipo-ideales de sufrirlo/gozarlo: formas que irían desde el hábito (ahora ya en nuestro sentido literal de rutinas, costumbres y competencias adquiridas), hasta las derivas miméticas en múltiples direcciones (Tarde y Latour) y toda la mencionada complejidad suadens con su intensa producción de heterogéneos entramados, tejidos, envolturas y atmósferas afectivas determinantes de múltiples procesos de subjetivación.

La Cultura no es sólo exterioridad coactiva físico-material, normativa y disciplinaria envuelta en un aura de seducción (que también lo es, desde luego) sino también, y de modo eminente, ese Otro paisaje bio-socio-espacial infinitamente más abierto, cambiante e impredecible — plagado de micropoderes, contrapoderes y resistencias tan ideológicas como físico-materiales- ligado a rutinas pero también a enjambres de imitación y a la aparición de esas nano-ontologías suadens en permanente becoming de microtexturas afectivas e intensas resonancias y complicidades emocionales. 
Si a esta condición le unimos el poder imprevisible de ciertos grandes y micro acontecimientos y todo tipo de circunstancias geográfico-urbanas locales, la acción de agentes (mediadores e intermediarios en el sentido latouriano) y la silenciosa actuación de dispositivos semiótico-materiales (Foucault y de nuevo Latour), —a menudo decisivos_-, es menester reconocer el carácter radicalmente abierto, imprevisible y azaroso de cualquier globalidad estructural del ME y su dependencia radical de las diferencias, derivas y derivadas locales imposibles de integrar (en el sentido matemático) en una gran explicación totalizadora.

Ahora bien, lo que ya no tiene el más mínimo sentido es seguir atribuyendo retóricamente a la Cultura o a la Sociedad (con mayúscula) en su primera significación unilateral durkheimiana - como curvatura del ETS y exterioridad coactiva semiótico-material disciplinaria - aquello que depende justamente de los otros poderes de la cultura o la sociedad (con minúscula) en su significación suadens de orden burbujeante y envolvente bio-socio-espacial.

Se olvida que la Cultura, en su primera acepción como pura exterioridad, hubiese sido absolutamente impotente para imponerse - en forma de sociedades despóticas y a menudo durante cientos de años- sobre los seres humanos sin el auxilio de la segunda tanto en su vertiente de aceptación más o menos activa (en forma de alguna modalidad de servidumbre voluntaria, alienación o consentimiento entreverado de protesta y malestar) como en términos de puro habitus en el sentido de Bourdieu o de contrapoder/resistencia (entre aquellos que se opusieron a ellas de mil modos).

Estamos ahora ante la desbordante riqueza (Potentia) de un polimórfico, complejo, contradictorio y tantas veces indecidible campo empírico bio-socio-espacial en cuyo ámbito los sujetos ni están necesariamente alienados ni simulan aceptación mientras por lo bajo murmuran, se burlan y conspiran contra los poderosos, ni tampoco se hallan comprometidos con una militancia revolucionaria sino más bien (¡como los amos y los poderosos!) envueltos y enredados en mil pliegues bio-socio-espaciales de signo familiar, laboral, pasional, amistoso, local o de cualquier otro carácter suadens en los que (se) les va la vida.

No, la gente no siempre aprende fatalmente a servir voluntariamente a los déspotas, ni tampoco se limita a simular estratégicamente ese sometimiento, aunque sin duda hay mucho de ello y de sus (in)consistentes mezclas. No, la clave de todo parece estar en otra parte: lo que mantiene casi siempre en el poder a los tiranos es que a menudo la tiranía (el dominio por la fuerza) se convierte en hábito en un sentido literal convencional (anterior al tecnicismo de Bourdieu) (como una suerte de costumbre o rutina frente a una sociedad naturalizada cuasi en términos meteorológicos o geomorfológicos en tanto que paisajes-curvaturas globales a los que hay que adaptarse) mientras que, simultáneamente, los individuos en el seno de sus microenvolturas se ocupan y se im-plikan en todo tipo de entramados y redes afectivas pegados los unos a los otros como una colonia de algas. Ahora bien, esa potencia bio-socio-espacial se inscribe necesariamente si pretende desplegarse y colonizar ese severo paisaje en la aceptación pragmática por parte de los sujetos de leyes, normas y valores políticos, ético- 
estéticos, religiosos y laborales dirigidos estratégicamente hacia su total sometimiento.

Lo que estamos sugieriendo no es que el estereotipo sexista de la mujer victoriana analizado críticamente por J. S. Mill o la irrespirable, totalitaria, sociedad franquista de la posguerra sean por ellos mismo fenómenos más o menos naturales que no requieran (como el antiguo esclavismo) la crítica más severa y una acción política radical. Más bien todo lo contrario. Lo único que queremos decir es que, en ningún caso, se debe recurrir en exclusiva a ninguno de los tres clichés mencionados (alienación y/o simulación de servidumbre voluntaria o, en su caso, rebelión o militancia revolucionaria) como si entre ellos agotasen la totalidad del espectro de las enmarañadas, oscuras y contradictorias relaciones de los sujetos y pequeños grupos con el Poder (Potestas). Frente a estos tres tópicos aparece otro potencia indómita: la Potentia spinoziana de esa desbordante, inagotable, riqueza bio-socio-espacial irreductible a cualquiera de estas fórmulas, aunque compatible con todas y cada una de ellas, en diferentes dosis, composiciones, maridajes e hibridaciones.

De ahí, también, la naturalidad de la pacífica transición política española, la caída del muro de Berlín o las actuales revoluciones democráticas de los países árabes. Sin embargo, lo cierto es que tan poco natural era antes, para grandes sectores de la población, el franquismo, el socialismo real o las dictaduras de los déspotas árabes del Mediterráneo como lo son ahora las exaltaciones democráticas oficiales en el Estado español compatibles con el máximo descrédito de una clase política implicada en múltiples casos de corrupción, refrendada por aquellos votantes que una y otra vez la sostienen con su voto; la ambigua incorporación a la Unión Europea de los antiguos países del este muchos de cuyos ciudadanos añoran el viejo orden o el entusiasmo revolucionario ciberactivista entre las jóvenes generaciones de estados como Túnez, Libia o Egipto deseosos no sólo de un nuevo Estado moderno sino también de alcanzar los estándares burgueses de la vieja Europa.

En breve: esa Otra Potencia bio-socio-espacial no sólo ha operado en el sistema de castas hindú, en el feudalismo o en el franquismo sino que opera también a pleno rendimiento en la actual democracia española y en cualquier otro régimen futuro. Algo que debería llevar a las ciencias sociales al reconocimiento definitivo del carácter lábil, huidizo y escurridizo de sus objetos tantas veces inaprensibles por la red de sus tautologías fundadoras pensadas desde la (¡esta vez si!) pretendida normalidad del Estado moderno. Más acá de toda apresurada teoría crítica las ciencias sociales deberían conceder, finalmente, que una gran parte de las ontologías híbridas y mestizas de lo social se les escapan y resultan inaccesibles e irreductibles a sus esquematismos pseudo emancipatorios.

Lo que en ningún caso parece tolerar el ME es la paladina indiferencia de tantos individuos y grupos frente a las grandes estructuras, instituciones y significaciones sociales de la modernidad triunfante; ante una naturaleza humana volcada filogenéticamente hacia lo local, lo microsocial, los pliegues del ETS y las envolturas. Esto es algo que las CCSS jamás perdonarán a los sujetos de car- 
ne y hueso, al lumpen marxista y a los suicidas no estrictamente durkheimianos: su incapacidad de estar a la altura de los grandes Estados Nacionales, de sus estadísticas y de sus ilusorias fantasías de un Poder directo sobre los individuos desanclados de sus tradicionales organizaciones, comunidades y estructuras locales.

Se olvida, asimismo, que — como escribió C Geertz (1973)—, la cultura, lo social o la sociedad no es una recién llegada a homo sapiens que se imponga como exterioridad sobre una salvaje naturaleza biológica considerada como lo completamente Otro de aquella, sino, justamente, aquello que ha transformado filogenéticamente (como causa y efecto a la vez) nuestras estructuras psicobiológicas. Es decir: la cultura y la sociedad no deben contemplarse como un artificial malestar sino también como un natural y delirante bienestar; no deben contemplarse exclusivamente como un poder represor sobre nuestros instintos sino como el origen de otros instintos y otros deseos tanto o más poderosos que aquellos que compartimos con el resto de primates.

No se quiere reconocer tampoco que el hecho indiscutible historicista, relativista y culturalista de la aparente singularidad y relativa inconmensurabilidad de las culturas por lo que respecta a sus contenidos no debe hacernos olvidar que todas ellas son producto de esa capacidad bio-socio-espacial que las convierte en variantes de una misma naturaleza humana.

\section{TRANSFORMANDO LA MATRIZ HEURÍSTICA DE LAS CIENCIAS SOCIALES}

El actual estado de las relaciones entre las ciencias sociales y la investigación psicobiológica muestra a las claras una doble evidencia. De una parte, un profundo y arraigado desencuentro, cargado de suspicacias ideológicas e incomprensión, sólo parcialmente sostenido en argumentos objetivos. De otra, la necesidad de promover un espacio interdisciplinar de debate que haga posible la incorporación efectiva de los resultados de la investigación bio-psico-social a los programas de investigación implementados en las ciencias sociales.

El desarrollo de la investigación naturalista en las tres últimas décadas ha puesto sobre la mesa un abundante y rico material empírico y teórico. Lamentablemente, esta literatura, básicamente anglosajona, permanece al margen de los círculos académicos e intelectuales continentales (los españoles no somos una excepción en esto), acumulando evidencias y desarrollos teóricos que reclaman una valoración atenta y fría de sus resultados. Existen poderosas razones para hacerlo pero, finalmente, una sola razón es suficiente: las ciencias sociales necesitan pensar a fondo la naturaleza humana. Resulta indispensable liberar este concepto del papel subsidiario y maldito que ha desempeñado hasta hoy y reclamar para él una centralidad explícita que nunca se le ha concedido en este ámbito. Y ha de ser así porque las ciencias sociales no pueden construirse, ni 
construir sus objetos, sin hacerse cómplices de una visión del hombre. Iluminar este vínculo, hacerlo explícito y enriquecerlo con las evidencias que la investigación naturalista tiene a su alcance resulta crucial.

Sin embargo, no puede negarse que para el científico social resulta difícil identificar el valor de las hipótesis naturalistas. Sociólogos, antropólogos, economistas e historiadores, entre otros, desconfían de la pertinencia que para sus respectivas disciplinas puede acreditar dicha investigación, pues por lo común conduce a vagas reflexiones introductorias, realmente improductivas para la investigación social empírica, o, por el contrario, se desliza hacia ambiciosas especulaciones deterministas y reduccionistas que, en su ambición, disuelven el espacio disciplinar que ocupan las distintas ciencias sociales.

Es más, de acuerdo con esta arraigada percepción, incluso en el caso de que pudieran establecerse rigurosamente algunos de los objetos de conocimiento que persigue el programa naturalista — esos universales rasgos de la naturaleza humana y sus avatares filogenéticos-, ninguno de ellos permitiría adentrarse más allá de la línea que da paso al ámbito del acontecer sociohistórico, pues éste es un espacio marcado por una compleja mezcla de restricciones materiales locales, facticidad social, singularidades personales, juegos de poder e inevitables dosis de indeterminación - histórica, imaginaria y praxeológica-, elementos todos que parecen situar lo social a salvo de cualquier determinación o regularidad natural.

Por ejemplo, ¿en qué sentido una teoría de los orígenes evolutivos de nuestra mente y de nuestro comportamiento puede desplegar los elementos necesarios para la identificación e interpretación de una secuencia de sucesos históricos como los que agrupamos bajo la expresión guerra civil española? ¿Cómo podría contribuir la más precisa reconstrucción de nuestra filogénesis al análisis sociocultural de fenómenos como el cambio social, el gusto, o el suicidio? ¿De qué manera, en fin, el más sutil y completo modelo del comportamiento humano surgido de la investigación naturalista podría dotarnos de lo necesario para elaborar una sólida etnografía de la escuela, de la práctica de la medicina hospitalaria o de una de aquellas añoradas poblaciones indígenas que estudió Malinowski?

En este ensayo defendemos la necesaria reconceptualización de algunos de los problemas del corazón teórico-metodológico de las ciencias sociales, precisamente de aquellos que subyacen a estos y otros interrogantes. Esta necesidad es especialmente urgente en todos aquellos ámbitos en los que el análisis sociocultural (histórico, antropológico, económico o sociológico) se apoya subsidiariamente en una determinada concepción de la naturaleza humana, lo cual es un hecho bastante habitual aunque pocas veces evidenciado.

En contra de la imagen popular - justificada en muchos casos- que atribuye a la investigación naturalista el propósito de dar cuenta de los fenómenos culturales como proyecciones a escala colectiva de una gramática profunda alojada en nuestros genes, nosotros sostenemos que lo que el programa naturalista ofrece al científico social es un nuevo conjunto reglas heurísticas - con permiso de Durkheim y Giddens- que prescriben ciertos compromisos teóricos y 
prohíben otros. O si se prefiere, un consistente sistema de alertas frente al uso especulativo de interesadas representaciones de la naturaleza humana, así como de otras nociones ideológicas y tropismos deterministas que anidan en la ciencia social estándar. Tales reglas no anulan la oportunidad de una ciencia social autónoma, cuyos objetivos son irrenunciables, ni pretenden reducir el espacio discursivo de las ciencias sociales al ámbito de lo epifenoménico, pero sí transforman de manera sustancial el abordaje de muchos de los marcos teóricos en los que las ciencias sociales se desenvuelven.

Presentamos a continuación tres campos de reflexión que pueden ilustrar nuestro propósito.

\section{a) Repensar la socialización}

El análisis de los procesos de socialización y, en general, de cualesquiera procesos de aprendizaje social exige toda una teoría implícita de la plasticidad humana. El Modelo estándar ha exagerado hasta límites extremos la maleabilidad de la naturaleza humana, negando la relevancia de nuestra peculiar constitución psicobiológica en la explicación de los fenómenos sociales. El individualismo, por su parte, ha subrayado ciertas disposiciones naturales, pretendidamente inextinguibles, como supuestos doctrinales desde los cuales modelizar la conducta humana. Sin embargo, el verdadero sentido y alcance de la plasticidad humana permanece oculto para las ciencias sociales.

La plasticidad cognitiva y conductual de nuestra especie no procede de nuestra independencia respecto del reino animal, del que formamos parte. No es, tampoco, el efecto emancipador de la cultura actuando sobre, y extinguiendo, unos restos instintivos primarios, mecánicos, deterministas e incivilizados, para edificar sobre ellos una segunda naturaleza más humana, abierta, racional, ética, profunda y extensamente social. Tampoco es, finalmente, el signo palpable de una realidad espiritual ajena a los dictados de la materia y sus leyes. Nuestra plasticidad es, simplemente, nuestro más particular y original producto evolutivo.

Para profundizar en el vínculo que anuda cultura y personalidad, de acuerdo con el lúcido insight que anima toda investigación social, resulta esencial mostrar cómo frente a una plasticidad de primer orden que enfatiza la prelación de lo social y colectivo sobre el individuo, existe otra, menos visible pero no menos importante, que mantiene en constante reestruturación nuestra identidad y que es el resultado de dos poderosas fuerzas: una endógena, consecuencia de nuestra arquitectura cerebral, de naturaleza modular, y en ella del papel de las emociones en la gestión del conocimiento y la conducta, y otra exógena, grupal, local y azarosa, enraizada en una forma de socialidad primordial u originaria que nos es propia, una instancia ésta que filtra y refracta cualesquiera otras experiencias y representaciones y que es la verdadera medida de nuestra naturaleza social.

De este modo, si la plasticidad de primer orden es la causa de ese efecto cul- 
turalista y sociologista - impresionista y platónico-, por el que se presenta al individuo como una instancia particular de alguna categoría orgánica o colectiva, la segunda forma de plasticidad es la responsable del modo en que los humanos nos relacionamos con y manejamos aquellas fuerzas, representaciones o retablos imaginarios que nos constituyen - roles, adscripciones de clase, creencias, competencias sociales, ideologías, criterios y preferencias, etc-, de acuerdo con pautas variables, poco predecibles y escasamente coherentes, que poco tienen que ver con la imagen que las ciencias sociales han volcado de un ser humano construido de una pieza y para siempre por la cultura.

La plasticidad que necesitamos incorporar a nuestros modelos y análisis de los fenómenos sociales es la responsable de que una y otra vez los actores sociales se muestren rebeldes frente a su destino social o presenten su perfil ideológico o conductual a medio hacer, como si su proceso de troquelado social se hubiera interrumpido antes de tiempo. Esta plasticidad es la única que puede armonizar de forma definitiva las aporías que atraviesan la teoría social y que impiden que, en las ciencias sociales, salgan las cuentas.

La plasticidad de la naturaleza humana no se ajusta a la idealización durkheimiana de la materia prima pues es mucho más profunda, enérgica, descentralizada, constante y transversal de lo que nunca pudo considerar el mismo Durkheim. La investigación neurobiológica y evolutiva nos muestran que la plasticidad posee una profundidad que no se agota en un estadio inicial, la infancia, o en ciertos momentos puntuales de nuestra vida en los que el individuo se encuentra preparado para absorber la sustancia cultural. Nuestra plasticidad debe adquirir un protagonismo mucho mayor del que hasta ahora le hemos otorgado, pues hemos de dar cabida en nuestros modelos de comportamiento social a unos actores que, por razón de su compleja plasticidad, no sólo se disponen a adquirir competencias — habitus_- aprender reglas de juego — lógicas prácticas - y actuar bajo sistemas de restricciones y fuerzas sociales objetivas - campos_-, sino que además se ven en la necesidad de desempeñar su acción de acuerdo con pautas motivacionales muy diversas - las que se corresponden con los diferentes contextos locales en que se sitúan-, implementando algoritmos cognitivos potencialmente divergentes - los que gobiernan las diversas estructuras cerebrales - y en climas emocionales dispares — que van desde la completa distancia empática a una participación vívida y sentida.

Es por esta razón por la que la aproximación estándar conduce a constantes paradojas y conflictos protagonizadas por sujetos inconsistentes cuya acción sólo responde parcialmente a lo que se espera de ellos, pues no puede dar cuenta de todos aquellos casos — potencialmente infinitos — en que las prácticas y competencias sociales de dichos actores se ven refractadas, transformadas o incluso anuladas de acuerdo con las necesidades de cada escenario local y, muy especialmente, bajo los poderosos efectos de la microsocialidad en la que cada cual experimenta sensu stricto cualesquiera contenidos, objetos y prácticas de una cultura. 


\section{b) La naturaleza del vínculo social}

Un segundo asunto crucial, íntimamente vinculado al anterior, consiste en la clarificación de la naturaleza del vínculo social. Esta tarea, por su parte, exige una visión completa de la socialidad humana construida sobre cimientos sólidos y evidencias empíricas y no sobre las especulaciones que alimentaron la imaginación filosófica desde Aristóteles a Rousseau, Hegel y Marx, pasando por Hobbes, Smith y J. S. Mill.

Las ciencias sociales se encuentran atravesadas por una equivocada consideración del individuo como átomo social, que se reproduce tanto en las tradiciones individualistas, en las que el origen de lo social se concibe como resultado no pretendido de la actividad de la mónada-sujeto, como en las tradiciones holístas y colectivistas, en las que el individuo, como realidad primera y bruta, es configurado por el organismo social mediante sus pregnantes potencias socializadoras. Tanto en unas como en otras tradiciones, el individuo es pensado como realidad radical.

Nosotros defendemos que ésta es una concepción viciada de origen pues ese individuo, el individuo monádico del individualismo tanto como el individuo materia prima del culturalismo colectivista, no es real. La exploración de la naturaleza humana, como ya intuyeran muchos pensadores, pone de manifiesto, elocuentemente, que el ser humano es un ser constitutivamente proyectado en sus relaciones sociales - hacia ellas y desde ellas. Nuestra socialidad, aquella que es propia de nuestra naturaleza, posee un perfil bien marcado por nuestra filogenia y dista bastante de las idealizaciones que filósofos y científicos sociales han hecho de ella. Y, sin embargo, es indispensable para comprender al hombre y su cultura.

La socialidad humana, no está mal recordarlo, no procede de ninguna superioridad ontológica, moral, estética o religiosa de la vida cooperativa sobre otras formas de vida; ni siquiera de una superioridad biológica. Nuestra socialidad es el resultado contingente de nuestra filogénesis, un proceso en el que la transmisión cultural como estrategia adaptativa (una cultura que funciona como sistema de herencia, que permite la acumulación de saberes y prácticas adaptativos entretejidos con otros claramente neutros y maladaptativos) se encuentra asociada a una ontogenia ralentizada que necesita e incentiva el vínculo familiar, a un sistema nervioso costoso, complejo y muy potente y a una predisposición para el aprendizaje social que requiere de intensas microinteracciones sociales.

La socialidad humana consiste en una red de relaciones de aprendizaje y cooperación, emocionalmente intensas y cuantitativamente limitadas -microsociales-, que se extienden articulando pequeños grupos de individuos, muchos de los cuales se encuentran, además, unidos por vínculos de parentesco y/o recirpocidad. Una pieza fundamental de esos procesos de interacción consiste en la búsqueda de reconocimiento y aprobación por parte de los otros, de aquellos que configuran los sistemas de relaciones privilegiadas en los que se inserta el indi- 
viduo. Los gestos explícitos o implícitos de aprobación y reprobación social que acompañan toda interacción, especialmente aquellas cuya finalidad específica es el aprendizaje o la cooperación, resultan cruciales en el proceso de transmisión cultural, optimizando la incorporación, sub especie local, de los contenidos culturales y prácticas sociales que dan cuerpo al backgraund de cada comunidad humana.

Esta forma de socialidad primordial, y no el individuo o lo social, es la que constituye el verdadero entramado ontológico de las colectividades humanas y, en consecuencia, es ella quien determina las condiciones objetivas mediante las cuales experimentamos - es decir, representamos, sentimos y actuamos en- cualesquiera instituciones y procesos socioculturales - tales como una guerra, una confesión religiosa o una práctica profesional-, pues actúa como condición de posibilidad y como medida real de todas nuestras vivencias.

Frente a la incesante hipertrofia cultural que desde hace diez mil años crece en torno al individuo y sus vínculos más íntimos y significativos, existe una dimensión tribal, comunitaria, radicalmente local, fluida y azarosa, emocionalmente intensa, que renace una y otra vez bajo los grandes ejes de la experiencia colectiva —el Estado, las iglesias, los mercados, la nación... (Maffesoli, 1990; 2007). Esta dimensión burbujeante y microsocial que se genera tantas veces en torno a fenómenos u objetos de escasa trascendencia histórica — la práctica de un deporte, el consumo compartido de un producto o un icono pop- nos recuerda que por debajo de las grandes estructuras sociales, cuya existencia e influencia sobre el destino de los actores sociales nadie discute, existe una trama microsocial que da cuerpo (ontológico) y sentido (bienestar) a nuestra particular existencia, pues es en su interior y bajo sus condiciones particulares cómo el individuo accede y experimenta cualesquiera otros fenómenos socioculturales.

Esta nueva ontología, centrada en las burbujeantes tramas microsociales en las que el individuo experimenta tanto su individualidad como su pertenencia al cuerpo social, no cierra el espacio discursivo de las ciencias sociales ni anula su lúcida comprensión de los vínculos entre estructura social y personalidad, por utilizar el viejo lenguaje funcionalista. Simplemente nos obliga a renunciar a los tropismos deterministas tan propios de la lógica sociologista y culturalista, al tiempo que nos abre a la comprensión de la inestabilidad e inconsistencia de los procesos sociales empíricos y nos permite recuperar de manera comprensible y no paradójica la perspectiva del actor social situado.

\section{c) Conocimiento y creencia}

Una tarea urgente para las ciencias sociales es dotarse de una genuina fenomenología de las creencias, pero no en tanto que investigación acerca de la creencia como contenido distinguible del saber o la superstición, sino como indagación acerca de lo que significa ser creyente, es decir, Homo suadens. Nada hay más urgente que indagar acerca de lo que significa creer. Como hemos 
mostrado en su momento, Homo suadens tiene su razón de ser filogenética en su extraordinaria capacidad para transmitir y recibir información cultural encapsulada en y entreverada de relieves valorativos. Sólo porque los procesos de aprendizaje y enseñanza ocurren de este modo y sólo porque hemos desarrollado ese segundo sistema de evaluación en el que la carga valorativa se instala en los contenidos mediante el juego paritario de la receptividad emocional de nuestra mente y el empuje aprobatorio y reprobatorio de la interacción social más elemental, la transmisión cultural ha sido posible tal y como la conocemos en nuestra especie.

Todo aquello que nos es dado por medio del aprendizaje, la imitación y la enseñanza se nos muestra situado sobre un plano perceptivo y comunicativo que nunca es neutro. Los contenidos de nuestro aprendizaje pasan ante nosotros moviéndose sobre una superficie irregular, sobre un mapa tridimensional con relieves, simas profundas, altas cumbres, parajes oscuros, unos, y luminosos, otros. Los contenidos de nuestros aprendizajes no están, como las fichas del ajedrez, situados en un plano en el puedan trazarse, mediante reglas de juego racionales, trayectorias algorítmicas entre ellos. Los contenidos de nuestros aprendizajes, muy al contrario, reposan sobre un tablero en el que casillas colindantes pueden encontrarse separadas por extraordinarias cordilleras valorativas que las hacen incomunicables, al tiempo que otras más distantes pueden verse conectadas por sinuosos toboganes.

Las ciencias sociales, comprometidas con su legítima vocación de mostrar los intereses territoriales, corporativos, económicos o geopolíticos afines a los programas políticos e ideológicos, en analizar su ejecución pública, en alumbrarlos desde su continuidad histórica con las tradiciones de pensamiento y acción y de sus compromisos con el progreso y el desarrollo de instituciones políticas justas, no pueden obviar, sin embargo, un asunto crucial, a saber, que las creencias formadas en los procesos de aprendizaje, mediadas por los vínculos sociales primordiales y fraguadas bajo las modalidades del Homo suadens, son el punto de partida de cualquier reflexión sobre nuestra realidad social, pues de lo contrario los votantes de los partidos políticos, los asociados a un sindicato, los adscritos a una clase socioeconómica o los seguidores de una confesión religiosa o laica se mostrarán siempre como individuos heterodoxos, cambiantes, inconsistentes en sus prácticas e infieles a los principios que les adscribimos, como si tuvieran el habitus a medio hacer y no fueran del todo conscientes de lo que son y de lo que deben ser.

Esta es la otra cara de la moneda. Las creencias de las personas nunca son lo que lo que la ciencia social les tribuye como propio de su habitus, su confesión, sus intereses, su capital cultural o su cuna. Las creencias reproducen estereotipos, representaciones imaginarias e intereses de clase, por supuesto, pero lo hacen refractando cada una de esas representaciones a través de los prismas de la socialidad originaria, esa que se cuece en las interacciones burbujeantes del espacio-tiempo social en que vivimos, ensamblando y reensamblando nuestros intereses, aprendiendo y desprendiendo, y por ello, la facticidad social que funda 
el ME de las ciencias sociales sólo lo es cuando se observa desde lejos, poblada por los objetos que el científico ha puesto previamente en ella. Contemplada desde la óptica de las ciencias sociales, esa facticidad se muestra consistente con las categorías que el investigador persigue: ideologías, clases, habitus, intereses corporativos, imaginarios sociales, etc. Se muestra como una facticidad reproductora, clonadora, estándar. Y, sin embargo, sabemos bien que de esta manera nunca salen las cuentas, pues más allá de la cartografía socioeconómica, sociopolítica o etnográfica que agrega y desagrega las poblaciones en grupos y clases -votantes progresistas, culturas primitivas, sistemas patrilineales, compradores responsables, nacionalistas moderados, marianistas y zapateristas, progesistas y conservadores, etc. - la ontología social que subyace a esos recortables no es la de las sustancias aristotélicas, sino un tejido social formado a partir de los vínculos del pequeño grupo, de burbujas e im-plikaciones que hacen que lo que las categorías científicas unifican y cosifican se refracte en formas y variedades diversas de esas mismas representaciones. ¿Qué sentido tiene decir conservador al voto que emite un alto funcionario del Estado de orígenes burgueses, un pequeño comerciante rural, el encargado de una cuadrilla de encofradores destajistas, un emigrante andaluz en el País Vasco o de un Guardia Civil castigado por el terrorismo?, ¿no se encuentra refractada la ideología de unos y otros, en cada caso, por las espesuras emocionales y praxeológicas de los vínculos en que esas representaciones que tejen su particular ideosincrasia fueron aprendidas e in-corporadas? Las ciencias sociales deben asumir la necesidad de una profunda reconceptualización de la ontología que subyace a sus categorías.

Las creencias no son formas débiles del saber, débiles en el sentido epistemológico. Tampoco son, en sentido inverso, formas fuertes, cargadas emocionalmente, frente a otras formas más neutras y objetivas. La creencia es la forma primigenia de todo saber, pues todo saber se adquiere como creencia, es decir, como una determinada configuración localizada espacio-temporalmente y corporalizada que conecta ciertos contenidos, ciertas prácticas y ciertos valores. Todo cuanto aprendemos lo aprendemos como tal configuración: así aprende un joven novicio los secretos de su fe, su vocación y su encaje institucional, mediante la convivencia y la interacción intensa con otros cuya mirada aprobatoria aprende a desear, cuyas emociones emula y cuyos gestos, expresiones e indumentarias imita; así aprende un niño a emocionarse con los colores del equipo de sus mayores y a sentir lo que debe sentir cuando contempla a un contrario o comparte con los suyos las consignas, los gritos y los espacios de encuentro; así aprendemos también a distanciarnos de lo extraño y ajeno y a vibrar con nuestra lengua, con los paisajes de nuestra tierra, sus aromas, su luz y sus sabores, hasta sentir que tales experiencias de bienestar y conexión emocional son el efecto que tales realidades (i?) bellas, buenas y verdaderas producen en nosotros como deberían producirlos en cualquier otro. El secreto de nuestros aprendizajes consiste en eso mismo, en que estamos hechos para atribuir las razones de nuestra seguridad cognitiva y de nuestro bienestar (o malestar) emocional sobre la (supuesta) objetividad (Verdad, Belleza y Bondad) de sus contenidos y no so- 
bre las sinergias fraguadas mediante el aprendizaje entre lo que creo, lo que hago y lo que siento.

Sin embargo, afirmar que todo cuanto es aprendido lo es de la misma manera no es exactamente lo mismo que afirmar que todo lo que se aprende debe merecer la misma consideración. La forma de transmisión cultural assessor y las distintas modalidades de Homo suadens nos permiten comprender cómo funciona el aprendizaje en nuestra especie y dan razón de la objetividad, inmediatez, evidencia y seguridad con que se presentan a cada individuo sus creencias y sus prácticas. Cualquier aprendizaje sigue este camino pues no hay otro. ¿Qué puede esperarse, pues, en relación a la determinación de los contenidos de lo que aprendemos? Mucho nos tememos que parecerá poca cosa, pero en lo que al debate público de ideas y valores se refiere, no hay otra cosa que la conveniencia de mostrar que toda propuesta ideológica entraña siempre una axiomática en la que sólo cabe discutir racionalmente acerca de las tesis derivadas (teoremas), pero no de sus axiomas o principios, que dependen enteramente de nuestras preferencias aprendidas. Que los fines que impulsan la alta política como aquellos otros que dirigen nuestras decisiones más cotidianas se escapan, en último término, a la disputa racional, es algo bien conocido y repetido en el marco de la reflexión humanística y científico-social. Hoy estamos en condiciones de entender de manera más precisa las razones de este hecho, razones que no son otras que las que se desprenden de un conocimiento más profundo de nuestra naturaleza común. Sin embargo, vale la pena insistir en que esta convicción no conduce a una suerte de entropía emocional y valorativa nihilista, pues ésta sí que está, por entero, fuera de nuestro alcance como seres humanos. El relativismo radical y profundo al que nos estamos refiriendo, un abismo al que todos preferimos no asomarnos, no sólo no se encuentra afectado por los gélidos vientos de la anomia, el cinismo o la falta de compromiso, sino que proclama, más bien, que tales actitudes no son propias de nuestra naturaleza y que homo suadens es siempre un ser de creencias, valores y compromisos. El nihilismo radical que acompaña a la peligrosa idea de Darwin (Dennet, 1995) no es el del fin de la historia y de las ideologías sino más bien al contrario, aquel al que se enfrente un Sísifo que una y otra vez se ve condenado a construir y reconstruir su mundo social con los mimbres que tiene, un mundo edificado sobre la fuerza (y la debilidad) de los vínculos sociales primordiales, aquellos que se nutren de las plikas y burbujas que teje con la complicidad de los otros.

La sociología del conocimiento, pues, nos ofrece un tercer frente de trabajo. También en este ámbito estamos en condiciones de redefinir algunos aspectos relevantes del debate teórico en torno a los vínculos entre conocimiento e interés, lenguaje e imaginario social, representación y estructura social. La ciencia social estándar ha centrado sus esfuerzos en mostrar los vínculos entre concepto, representación e ideología, por una parte, y estructura social o habitus, por otra.

El énfasis puesto en la determinación estructural de nuestras formas de representar y habérnoslas con lo real - formas impuestas de arriba abajo y de fue- 
ra a dentro - ha ocultado otra dimensión esencial en la formación y mantenimiento del conocimiento. Si la construcción social del conocimiento resulta crucial, no es menos necesario enfatizar las dimensiones cognitivas, emocionales y valorativas, últimamente bio-psico-sociales, que, entreveradas en los intensos procesos de aprendiza social, impregnan y dan forma a toda representación. El reconocimiento de este hecho, fuertemente respaldado por la investigación naturalista, nos permite visualizar dos fenómenos de la mayor relevancia, no siempre contemplados. En primer lugar, mostrar cómo todo conocimiento anida en la mente humana bajo la forma de la creencia, tiñendo de valor y carga emocional, desde su misma génesis, toda representación, toda preferencia, todo criterio. En segundo lugar, que cualesquiera contenidos culturales - representaciones, prácticas o preferencias - reconocidos y reconocibles como señas de identidad de una colectividad humana se adquieren y se instalan en las mentes de los individuos bajo las condiciones particulares de la trama ontológica — microsocial — mediante la cual han sido transmitidos, por lo que la aparente homogeneidad que proyecta la noción de habitus - u otras equivalentes - sobre un grupo humano queda profundamente relativizada por el efecto local y azaroso de las condiciones particulares en las que acontecen tales procesos de aprendizaje. Detengámonos algo más en estos dos fenómenos.

Una conceptualización veraz y completa de los procesos de aprendizaje exige enfatizar su dimensión valorativa. Todo conocimiento, representación, práctica o criterio es adquirido por el individuo en asociación con una determinante carga valorativa y emocional. La exploración, la imitación, el descubrimiento y la enseñanza que incesantemente tienen lugar en el medio cultural se encuentran entrecruzadas por poderosas asimetrías valorativas (asimetrías producidas por los dos generadores de valores y preferencias de los que estamos provistos, el sistema evaluador que reside en la parte más antigua de nuestro cerebro como guía para el aprendizaje individual y el más reciente y singular que se articula sobre la aprobación y reprobación a las que nos someten los otros). Las formas de aprendizaje social más característicamente humanas se producen como consecuencia de y mediante una descarga emocional que nos hace percibir una realidad con relieves y aristas, una realidad profundamente asimétrica. Mediante nuestras propias impresiones placenteras y displacenteras, pero también mediante nuestra disposición a incorporar el juicio valorativo de los otros como parte esencial de nuestra propia valoración, percibimos los objetos, las prácticas y las creencias, propias y ajenas, cargados de valores. Estos valores, a veces, se refieren a dimensiones utilitarias y pragmáticas; otras, a juicios no reducibles a criterios de utilidad, pero en todo caso son resultado de una mecánica cognitiva seleccionada por sus rendimientos adaptativos.

Nuestra naturaleza nos ha dotado de una extraordinaria capacidad para experimentar nuestros aprendizajes atravesados por intensas cargas emocionales cuya misión es conseguir que aquello que nos es dado - mostrado, enseñado, ofrecido - en el marco de los vínculos de la socialidad primordial —interacciones burbujeantes, en los entornos espaciotemporales en los que construimos 
nuestras intimidades - nos resulte cargado con los valores de lo Verdadero, lo Bueno y lo Bello y aprendamos a desearlo y a experimentar placer y bienestar con su ejecución y presencia y displacer y malestar cuando faltamos a su exigencia. Esta es la razón por la cual todo conocimiento, toda representación, toda práctica social, poseen la naturaleza de la creencia

Así pues, la carga valorativa que acompaña todo acto de nuestra conciencia es, antes que característica de una clase social, de una profesión o de un credo, consustancial a nuestro aprendizaje. Las ciencias sociales han sido perfectamente conscientes de la presencia de esta carga valorativa y han identificado las intensas afinidades entre creencias, prácticas y valores; estas afinidades han sido pensadas por las disciplinas sociales bajo las formas del ídolo y el prejuicio, la ideología, los intereses de clase, la falsa conciencia, las epistemes, el habitus o el imaginario colectivo. El científico social ha percibido nítidamente el vínculo que liga creencias, prácticas y valores, comprendiendo, además, que estos últimos no sólo se manifiestan como entidades abstractas, en tanto que propiedades objetivas de las cosas, sino también, y quizás antes, como sensaciones fisiológicas, como cambios en el metabolismo, como reacciones viscerales, como valores corporalizados (in-corporados). Así lo hace Durkeim, por ejemplo, al estudiar las efervescencias colectivas que tienen lugar en los fenómenos religiosos y así lo señala constantemente Bourdieu al enfatizar cómo el habitus, estructura estructurante, no puede reducirse al ámbito de la conciencia o el concepto, pues penetra toda nuestra experiencia corporal como sistema de disposiones y esquemas perceptivos, motrices, sensitivos y de preferencia. Sin embargo, esta conceptualización estándar, como vemos, no es suficiente.

El segundo fenómeno que debemos enfatizar hace referencia a la recepción o interiorización de las representaciones sociales por parte de los sujetos. Nuestras relaciones sociales juegan un papel trascendental en la formación del conocimiento, como bien sabían a su manera Marx, Durkheim o Weber. Su trascendencia se debe a que ellas son el vehículo y el medio en el que acontece el aprendizaje de cualesquiera contenidos culturales - conceptuales, actitudinales, procedimentales o emocionales. Estos procesos de aprendizaje nos remiten, por una parte, a los grandes retablos culturales de los que proceden los contenidos aprendidos por los individuos como miembros de una colectividad, así como de las estructuras sociales en las que tales sujetos se insertan. Sin embargo, la ciencia social estándar ha olvidado indagar en estas mismas relaciones sociales contempladas desde la óptica de nuestra socialidad originaria, es decir, como mediaciones microsociales necesarias y determinantes de la aprehensión de tales contenidos culturales. Esta mediación tiene lugar siempre bajo las azarosas modalidades locales que adopta nuestra socialidad. Dicho de otro modo, la transmisión de los contenidos culturales propios de una colectividad humana acontece siempre bajo las condiciones materiales y simbólicas introducidas por el tejido microsocial que constituye su entramado ontológico, por lo que el aprendizaje social y la transmisión cultural son fenómenos que no pueden ser analizados al margen de los avatares locales, tribales, comunitarios, microsociales, en los que 
tienen lugar tales procesos. Es por ello por lo que los miembros de una misma colectividad pueden reconocerse y ser reconocidos como jugadores de un mismo juego (Wittgenstein) o poseedores de un mismo habitus (Bourdieu), sujetos socialmente competentes en suma, al mismo tiempo que su disposición particular - en la que intervienen decisivamente las condiciones locales, las representaciones y emociones aprendidas que acompañan a sus prácticas sociales- puede encontrarse a gran distancia unas de otras.

\section{CODA: DESEO DE SER PIEL ROJA}

Si uno pudiera ser un piel roja siempre alerta, cabalgando sobre un caballo veloz, a través del viento, constantemente sacudido sobre la tierra estremecida, hasta arrojar las espuelas porque no hacen falta espuelas, hasta arrojar las riendas porque no hacen falta riendas...

\section{F. Kafka, El deseo de ser piel roja}

Woody Allen relata en Zelig, - con formato de un falso documental que transcurre en los años veinte del siglo pasado- la vida de Leonard Zelig, un hombre con un poder empático desmesurado; un caso literal de hombre camaleón capaz de mimetizarse con todo aquél con quien entra en contacto; un sujeto que cuando alterna con judíos le salen barbas, trencillas y caireles; se convierte en católico ante la presencia de Pío XI y en convencido nazi en el entorno de A Hitler.

Se trata sin duda de una de las películas más sugerentes y misteriosa de la historia del cine, pudiendo verse en ella tanto el comienzo de la era del consumo, la alienación y la rebelión de las masas en el sentido de Ortega y Gasset como la aparición de nuevos síndromes de extrema inseguridad y ansiedad que comenzaban a aquejar a sectores de las clases medias. Diagnóstico y tratamiento psicoanalítico hilarante que sufrirá el propio Zelig a manos de la ambiciosa doctora Fletcher.

Sin embargo, la extraordinaria comicidad de un personaje semejante ha impedido hasta ahora una mínima reflexión sobre el verdadero significado del mimetismo, la imitación y los aprendizajes de valores en los procesos convencionales de socialización estudiados por los científicos sociales. Después de todo, quizás, si descontamos tanto la inmediatez del mimetismo como su compulsiva seriación, no parece que haya grandes diferencias entre Zelig y cualquiera de nosotros.

El hombre como especie se caracteriza ante todo por su capacidad para socializarse en cualquier cultura. Lo cual fue posible por la facultad desarrollada durante su filogénesis para adquirir un lenguaje y crear poderosas ligaduras y sinergias entre lo que hace lo que siente y lo que piensa, forjándose una identidad social. Las ciencias sociales han captado perfectamente esa capacidad pero no han explorado suficientemente hasta qué punto sigue activa y operante durante 
toda la vida de un sujeto como muestran D. Quijote y M. Bovary: dos excelentes ejemplos de lo que R. Girard ha llamado deseo mimético.

Las ciencias sociales, además de prestar escasa atención a esa capacidad de transformarnos radicalmente en contacto con otros han recurrido a términos equívocos como interiorización para explicar cómo alguien se convierte en miembro de una cultura y adquiere cierta competencia cultural.

En contra de lo que dicen los manuales de sociología, cuando un individuo llega a ser miembro de una sociedad no absorbe entidades fantasmales como $L a$ Cultura o La Sociedad sólo existentes como tales en su pseudo idealidad platónica en las teorías de los científicos sociales. El sujeto adquiere más bien una relativa competencia social en el ámbito local de un grupo de referencia con el que se halla ligado afectivamente; aprendiendo a comportarse y a autoevaluarse en interacción cotidiana con los demás e incorporando los valores del grupo en contextos pragmáticos locales. Algo perfectamente compatible con abismales diferencias en las representaciones subjetivas y, sobre todo, en el grado de implicación emocional (desde la indiferencia hasta la pasión) con el cual cada sujeto vive y experimenta los usos sociales, las instituciones y las grandes significaciones culturales estudiadas por antropólogos y sociólogos. El mito de la $a b$ sorción de la Cultura no es más que una fantasía logocéntrica.

Además, los científicos sociales — desde K. Marx a E. Durkheim- han concedido unilateralmente todo el protagonismo en la socialización a la cultura. A diferencia de L Feuerbach que explicaba el origen de los dioses como una creación de los hombres que terminaba por tiranizarlos, los científicos sociales no parecen dispuestos a reconocer que la cultura sea también causa y efecto a la vez de la naturaleza humana.

Así, Marx disuelve al sujeto en la totalidad de las relaciones sociales y Durkheim se refiere a los hechos sociales como exterioridades coactivas actuando al modo de formas sustanciales masculinas sobre una individualidad concebida como materia prima femenina infinitamente moldeable. De esta guisa, el modelo estándar en ciencias sociales, - haciendo caso omiso de autores como G Tarde, R Girard, M Maffesoli, Todorov o P Sloterdijk-, niega por completo toda actividad al sujeto y toda virtualidad constructiva a la condición humana.

Esta hipertrofia de la esfera cultural conduce de manera fatal a dramatizar las diferencias entre las culturas como si éstas fuesen entidades estancas e impermeables, intraducibles e irreductibles las unas a las otras: si la naturaleza humana no es más que una facultad pasiva para dejarse penetrar por la cultura, las diferencias interculturales lo son todo y ya estamos definitivamente atrapados por el construccionismo posmoderno de las pequeñas, autistas, infinitas, diferencias.

Dos ejemplos bastarán para ilustrar lo que decimos. El primero de ellos se refiere a las relaciones del hombre con la razón o el Lógos, mientras que el segundo remite a las relaciones con Eros. Por lo que respecta a la razón, la historia de la filosofía suele describir correctamente la experiencia antigua de la misma, —el Lógos desde Platón a Plotino-, como lo completamente otro tanto del Ver- 
bo cristiano hecho carne como de la res cogitans cartesiana, para no hablar de los abismos insalvables que la separarían del taoísmo o del budismo tibetano. Y está en lo cierto. El Lógos - la manera propiamente humana de percibir, categorizar y razonar - es endiabladamente plural y se ha experimentado y construido de muchas maneras. Pero en los últimos años investigadores como P. Hadot, M. Foucault, G. Steiner e I. Gómez de Liaño han ido rescatándonos del jardín hechizado de las puras diferencias conceptuales, mostrando hasta qué punto tales construcciones se basaron, sin embargo, en unas mismas complicidades emocionales, vinculadas a sofisticados aprendizajes deseantes y a ciertos lugares, objetos, artes y tecnologías del yo, causa-efecto de similares procesos de subjetivación mimética en torno a algún maestro-gurú y su selecto grupo de iniciados.

Del mismo modo, —nos advierte J. A. Nieto, —el antropólogo de la sexualidad más lúcido y brillante de nuestro país-, en el campo de Eros los actos homosexuales tendrían distinta lectura e interpretación, significados radicalmente diferentes, según la sociedad en que se manifiesten: la Grecia de Homero, el Japón feudal, los azande de Sudán, los sambia de Papúa Nueva Guinea, los hijras de la India, los xanith de Omán, el we "wha de los zuñi de Norteamérica o los gays del barrio de Chueca de Madrid. A lo cual, desde luego, tampoco nada habría que oponer. Salvo que,-y esto es lo decisivo-, todos estos ejemplos no deberían interpretarse por ciertos públicos fundamentalistas posmodernos como producto exclusivo de organizaciones e imaginarios sociales diferentes capaces de construir, por ellos mismos, distintas, incomparables, homosexualidades

¡Como si Zelig no pudiese también transformarse en devoto camaradaamante de samurái o en atractiva berdache (hombre-mujer) de los indios zuñi y, sobre todo, como si el ethos erótico de los samurais (y/o de los propios zuñi) no fuese causa/efecto previo de la creación social colectiva de otros tantos Zelig del pasado! Como sucede con el Lógos también en el caso de Eros suele olvidarse el papel decisivo de los aprendizajes, las derivas imitativas y los procesos miméticos de subjetivación.

El posmodernismo cultural, en fin, sólo parece dispuesto a ver una espiral autista de diferencias que se multiplican sin cesar por ellas mismas. Pues bien, lo cierto es que por debajo de la innegable, indiscutible, complejidad y multiplicidad cultural, hay al menos un rasgo determinante que ha hecho posible el espejismo de los poderes construccionistas de la esfera cultural.

Desde A. Smith y G.W.F. Hegel, como ya hemos afirmado, las ciencias humanas siempre han percibido que el deseo del hombre es un deseo aprendido: el deseo de poseer y exhibir aquello que suscita el deseo de los otros y ser reconocido por ellos. Es decir, nuestra condición de homo suadens, heredero azaroso de una mente sapiens-demens, fabuladora, cosificadora, esencialista y modular que activa simultáneamente programas y algoritmos contradictorios; una mente arraigada afectivamente en micro socialidades locales, aquejada de profundas inconsistencias cognitivo-emocionales y que, a la vez que mimetiza, altera y distorsiona - aunque sea mínimamente - toda transmisión cultural.

Al igual que D. Quijote, M. Bovary y Zelig, cualquiera,._-incluido F. Kaf- 
ka_, arrastrado por el deseo de ser piel roja, puede mimetizarse y entrar en flujo real o imaginario - con una tribu apache, con el Lógos erótico de Sócrates como cuenta Platón en el Fedro, con una célula estalinista como narra A. Koestler en su autobiografía o con un grupo yihadista semejante al que perpetró los atentados del 11-M. En todos estos procesos de subjetivación los sujetos sufren una triple, idéntica, metamorfosis de su ethos, de su entera sensibilidad corporal y de su previa racionalidad como si volviesen a nacer de nuevo. Y, por esa razón, en todos ellos también se ligan y anudan, respectivamente, en tanto que creyentes, - homo credens, es lo que mejor define al hombre- las decisivas mediaciones de lo bueno, lo deseable y lo verdadero; mediaciones tan humanas y sublimes como virtualmente excluyentes y totalitarias que nos han hecho ser lo que somos y, ay, continuamos siendo.

Dimensiones decisivas que nos llevan a reconocer — a pesar de las dramáticas diferencias en los contenidos histórico-culturales de esos tres valores implicados en nuestra hominización - rasgos de humanidad incluso en el rostro y la conducta de aquellos que nos resultan más intolerablemente ajenos e inhumanos $\mathrm{y}$ en las que se fundan los derechos llamados humanos que, finalmente, nos hemos concedido los unos a los otros.

Tal es la capacidad que compartimos desde hace decenas de miles de años y que subyace - como causa y efecto a la vez - en todos los llamados procesos de socialización, subjetivación y re-subjetivación. El hombre desea el deseo del otro e identifica el intenso placer y bienestar que le produce ese reconocimiento con alguna (a menudo peligrosa, explosiva) mezcla local del Bien, la Belleza y la Verdad: tal es la otra clave tragicómica de la cultura, de la socialización y aquello que debería constituir un límite prudente y definitivo al actual narcisismo posmoderno entregado, todavía, a la perezosa, dulzona, exquisita, inopia de las pequeñas, grandes, inconmensurables diferencias interculturales.

\section{REFERENCIAS}

Aguiar, F. (2004): «Teoría de la decisión e incertidumbre: modelos descriptivos y normativos», Empiria, no 8, pp. 139-160.

Boudon, R. (1998a): «Social mechanisms without black boxes», en Hedstrom, P; Swedberd, R. (eds.), Social mechanisms. An Analytical Approach to Social Theory, New York, Cambridge University Press.

- (1998b): «Limitations of Rational Choice Theory», American Journal of Sociology, vol. $104, \mathrm{n}^{\mathrm{o}} 3$.

Bourdieu, P. (1988): La distinción. Criterio y bases sociales del gusto. Madrid, Taurus.

- (1991): El sentido práctico. Madrid, Taurus.

Boyd, R., y Richerson, P. J. (1985): Culture and the Evolutionary Process, Chicago, The Chicago University Press.

- (1996): «Why culture is common but cultural evolution is rare?» Proceedings of the British Academy, 88, pp. 77-93.

- (2001): «Culture is Part of Human Biology. Why the Superorganic Concept Serves 
the Human Sciences Badly», en M. Goodman and A. S. Moffat(Eds.) Probing Human Origins. The American Academy of Arts \& Sciences, Cambridge, MA,

CAstro, L., y Toro, M. A. (1995): «Human evolution and the capacity to categorize» Journal of Social and Evolutionary Systems, 18, pp. 55-66.

- (1998): «The long and winding road to the ethical capacity», History and Philosophy of the Life Sciences, 20, pp. 77-92.

- (2002): «Cultural transmission and the capacity to approve or disapprove of offspring's behaviour», Journal of Memetics -Evolutionary Models of Information Transmission, 6.

- (2004): «The evolution of culture: from primate social learning to human culture», Proceedings of the National Academy of Sciences, USA, 101, pp. 10235-10240.

Castro, L., Castro-Nogueira, L., Castro-Nogueira, M., Toro, M. A. (2009): «Darwinismo y ciencias sociales: Una interpretación naturalista de la cultura», Ludus Vitalis, vol. XVII, núm. 32, pp. 281-306.

Castro, L., Castro-Nogueira, L., Castro-Nogueira, M. y Toro. M. A. (2010): Cultural transmission and social control of human behavior. Biology and Philosophy 25, pp. 347-360.

Castro, L., López-Fanjul, C. y Toro, M. A. (2003): A la sombra de Darwin: Las aproximaciones evolucionistas al comportamiento humano, Madrid, Siglo XXI Editores.

Castro, L., Medina, A. y Toro, M. A. (2004): «Hominid Cultural Transmission and the Evolution of Language», Biology and Philosophy, 19, pp 721-737.

Castro, L., Castro Nogueira, L. y Castro Nogueira, M. A. (2008): ¿Quién teme a la naturaleza humana? Homo suadens y el bienestar en la cultura: biología evolutiva, metafísica y ciencias sociales, Madrid, Tecnos.

Castro-Nogueira, L., CAstro-Nogueira, M. y Morales, J. (2005): Metodología de las ciencias sociales. Una introducción crítica, Madrid, Tecnos.

CAstro-Nogueira, M. A., CAstro, L. y Toro, M. A. (2010): Evolución y cultura: una aproximación naturalista a las ciencias sociales. Endoxa, 24, pp. 219-246.

Cosmides, L. y Tooby, J. (1989): «Evolutionary Psychology and the Generation of culture, Part II. Case Study: A Computational Theory of Social Exchange», en Ethology and Sociobiology 10, pp. 51-97.

- (1992): «The Psychological Foundations of Culture», pp. 19-136, en BARKOw, J., The adapted mind: Evolutionary psychology and the generationof culture, New York, Oxford University Press,.

- (1994): «Evolutionary Psychology. A premier». Este texto puede ser consultado en la web del Centre for Evolutonary Psychology, de la Universidad de California, http://www.psych.ucsb.edu/research/cep/primer.html

DARwIN, Ch. (1985): El origen de las especies, Barcelona, Planeta-Agostini.

- (1998): El origen del hombre, Madrid, Edimat.

DennetT, D. (1995): Darwin's Dangerous Idea Evolution and the Meanings of Life, New York, Simon and Schuster.

DoBZHANSKKY, Th. (1973): «Ethics and Values in Biological and Cultural Evolution», Zygon: Journal of Science and Religion, 8, pp. 261-281.

DurKHeIM, E. (1987): Las reglas del método sociológico, Madrid, Akal.

- (1993): Las formas elementales de la vida religiosa, Madrid, Alianza.

- (1995): La división social del trabajo, Madrid, Akal. 
ELSTER, J. (1991): Tuercas y tornillos Una introducción a los conceptos básicos de las ciencias sociales, Barcelona, Gedisa.

- (1997): Egonomics, Barcelona, Gedisa.

Foucault, M. (1981): Las palabras y las cosas. Madrid, Siglo XXI.

- (2006): Historia de la locura en la edad clásica, Barcelona, FCE.

GEERTZ, C. (1973): The Interpretation of Cultures, New York, Basic Books.

Gómez, A. (1997): «Microfundamentos de la explicación social», en CRUZ, M. Acción humana, Barcelona, Ariel.

HIRSCHFELD, L. y Gelman, S. (Eds.): Mapping the Mind : Domain specificity in cognition and culture, New-York, Cambridge University Press, 1994.

Hollis, M.: Filosofía de las ciencias sociales.Barcelona, Ariel, 1998.

Lewontin, R. C., Rose, S. y Kamin, L. J. (1987): No está en los genes, Barcelona, Crítica.

Lumsden, C., y Wilson, E. O. (1981): Genes, Mind and Culture, Cambridge, MA, Harvard University Press.

Lumsden, C., y Wilson, E. O. (1983): Prometean Fire. Harvard University Press, Cambridge, MA (Hay traducción castellana: El fuego de Prometeo, Fondo de cultura Económico, 1985).

MAFFESOLI, M. (1990): El tiempo de las tribus, Barcelona, Icaria.

- (2007): El crisol de las apariencias, Buenos Aires, Siglo XIX.

MALINOWsKI, B. (1986): Crimen y costumbre en la sociedad salvaje, Barcelona, PlanetaDe Agostini.

- (1994): Magia, ciencia y religión. Barcelona, Editorial Ariel.

MEAD, M. (1963): Sex and temperament in three primitive societies, New York, William Morrow.

Nieto, J. A. y Castro Nogueira, L.: «El Cableado Neuronal Innato de Pinker Repudia la Cultura: Intertextualidad e ínter sexualidad», EMPIRIA. Revista de Metodología de Ciencias Sociales, 11: 133-173, 2006.

Noguera, J.A. (2003): «¿Quién teme al individualismo metodológico», Papers, 69, pp. $101-132$

Pinker, S. (2005): La Tabla Rasa, Barcelona, Paidos.

Rendell, L., Boyd, R. et al. (2010): «Why Copy Others? Insights from the Social Learning Strategies Tournament», Science, 5975, pp. 208-213.

Richerson, P. J., y Boyd, R. (2005): Not By Genes Alone: How Culture Transformed Human Evolution, Chicago, University of Chicago Press.

SAHLINS, M. (1982): Uso y abuso de la biología. Una crítica antropológica de la sociobiología, Madrid, Siglo XXI.

SEN, A. (1982): «Behaviour and the concept of preference», en Sen, Choice, Welfare and Measurement, Oxford, Blackwell, pp. 54-73.

- (1986): «Los tontos racionales», en F. HAHN y M. Hollis, Filosofía y teoría económica, México, FCE, pp. 172-217.

SIMON, H. (1990): «A mechanism for social selection and successful altruism», Science 250 (4988), pp. 1665-1668.

SLOTERDIJK, P. (2000): Normas para el parque humano, Madrid, Ediciones Siruela.

- (2003): Esferas I, Madrid, Siruela.

- (2004): Esferas II, Madrid, Siruela.

- (2006): Esferas III, Madrid, Siruela.

SPERBER, D. (2005): Explicar la cultura. Un enfoque naturalista, Madrid, Morata. 
TARDE, G. (1890): Les lois de limitation, Paris, Alcan.

- (1898): Les lois socials. Esquisse d'une sociologie», Paris, Alcan.

TODOROV, S.: La vida en común.

TOLSTOI, L.

Tomasello, M. (1999): The Cultural Origins of Human Cognition, Cambridge, MA, Harvard University Press.

Tooby, J. y Cosmides, L. (2005): «Conceptual Foundations of Evolutionary Psychology», en David M. Buss (Ed.) The Handbook of Evolutionary Psychology, Hoboken, Wiley.

Waddington, C. H. (1960): The Ethical Animal. London, George Allen \& Unwin Ltd. (Hay traducción al castellano: El animal ético, EUDEBA, 1963). 